\title{
Theory of Mind: Towards an Evolutionary Theory
}

\author{
Ioannis Tsoukalas ${ }^{1}$
}

Published online: 7 August 2017

(C) The Author(s) 2017. This article is an open access publication

\begin{abstract}
Theory of mind is an important mental faculty. However, despite almost half a century of research, we only have a limited understanding of its evolutionary past. The present article proposes a novel hypothesis on the origin of this unique human capacity. According to this hypothesis theory of mind descended from two, closely related, defensive reactions, namely tonic immobility and immobilization stress. Both reactions are conserved in many vertebrate species and are highly prevalent in immature individuals. They are produced by a combination of manual handling and restraint (common in many nursing activities) and implicated in the management of stressful encounters. Most importantly, they have been shown to facilitate eye-contact, gaze-following, and intentional attributions. These traits, and several others detailed in the text, make them prime candidates in the search for the origin of theory of mind. The article presents conceptual arguments and empirical facts in support of this hypothesis.
\end{abstract}

Keywords Theory of mind · Evolution · Neoteny $\cdot$ Eye movements · Tonic immobility $\cdot$ Immobilization stress $\cdot$ REM sleep - Supine position · Parasympathetic system .

Domestication $\cdot$ Prefrontal cortex

"The eyes are the mirror of the soul"- Yiddish proverb

"The face is a picture of the mind with the eyes as its interpreter"- Marcus Tullius Cicero

Ioannis Tsoukalas

ioannis@socant.su.se; jannistvd@hotmail.com; http://

www.socant.su.se

1 Department of Social Anthropology, Stockholm University, 10691 Stockholm, Sweden

\section{Introduction}

A major development in cognitive neuroscience was the realization that humans, along with some primates, have a theory of mind (Premack and Woodruff 1978; Leslie 1987). Having a theory of mind (ToM) implies the ability to see others as intentional beings; to see their actions as motivated by mental states. It also entails the realization that the mental states of others may differ from one's own. Such mental states function as working hypotheses in the ongoing explanation and prediction of observable behavior, both one's own and that of others. This ability appears very early in life and seems to play an important role in the subsequent development of human language and social cognition.

A pertinent question is how this "mindreading" feat is accomplished, especially during infancy when sophisticated means of communication are not present. An intriguing answer, supported by considerable research, is that it is accomplished by the perceptual processing of the human face. The human face is very expressive and emits a number of distinctive and universal cues which signify internal states of the organism (e.g., joy, sadness, fear), cues which can be used by onlookers to make relevant attributions (Haxby et al. 2002; Ekman 2003; Gliga and Csibra 2007). A region of the face that is particularly relevant in this regard is that of the eyes. Registering and interpreting the eye movements of others can yield a rich harvest of information as to other people's feelings, intentions and thoughts (Kendon 1967; Pitcairn and Eibl-Eibesfeldt 1976; Baron-Cohen et al. 1997).

Not surprisingly, infants seem to have an inborn proclivity to focus on precisely this region of the face. Actually, they are mesmerized by the eye region and systematically seek eye contact and follow other people's gaze. Given that they are hardly capable of any other purposeful motor activity this asymmetry in sensorimotor capabilities is noteworthy. This ability to 
connect eye movements to internal states of mind is deemed so important that it has been called by some the "Holy Grail" of developmental psychology (Meltzoff and Brooks 2007: 217).

\section{Control Mechanisms}

Closer study of this faculty has revealed that it is controlled by two distinct neural circuits. The first circuit is subcortical. It passes through the retina, the superior colliculus, the pulvinar and the amygdala. The existence of this pathway is supported by a wide array of evidence, from magnetoencephalograms and imaging studies to intracranial recordings (Fletcher et al. 1995; Senju and Johnson 2009a; Shepherd 2010). The responses emanating from this pathway precede those from the cortex by several milliseconds; they are, to borrow an expression of Joseph LeDoux (1996), "quick and dirty." An interesting aspect of this pathway is its modular character: it is informationally encapsulated and responds to proprietary input. For example, it is insensitive to the kind of information activating the cortical structures (e.g., contextual information) while, on the other hand, being hypersensitive to particular kinds of stimuli (e.g., fearful faces).

The superior colliculus, in particular, has a special relationship to eye movements. This area of the midbrain controls several types of eye movements: fixations, smooth pursuit, vergence, and saccades (Kustov and Robinson 1996; Wallace et al. 1998; Lunenburger et al. 2001). In naturalistic settings, these eye movements are often related to speciesspecific predator or prey reactions, like orienting the head or body in rats and bats, tongue-strikes towards prey in frogs, and fang-strikes in snakes. Further, the superior colliculus also seems to control the timing of REM sleep, one of the mammalian sleeping stages (Miller et al. 1998, 1999).

The second circuit controlling ToM is cortical. It includes the medial prefrontal cortex, temporal pole, superior temporal sulcus, temporal parietal junction, and fusiform gyrus. The responses emanating from this pathway are much slower and highly sensitive to contextual information and task demands. They are primarily orchestrated by the dorsolateral prefrontal cortex and have the character of a top-down modulation of perceptual and sensorimotor processing based on emotional and mnemonic associations (Fletcher et al. 1995; Senju and Johnson 2009a; Shepherd 2010).

\section{The Question of Origins}

The ability to see others as cognizant and intentional beings, to have a ToM, is an important cognitive faculty. For almost half a century its role in social cognition has been widely acknowledged and extensively researched (Premack and Woodruff 1978; Baron-Cohen et al. 1997; Meltzoff and Brooks 2007). Despite this, however, we lack a solid understanding of its evolution. The few theories available are of a mostly functionalist character and claim that ToM evolved to satisfy the demands of social cognition. This is a rather unsatisfactory state of affairs. The above introduction, although brief, gives some hints as to where to start looking if we want to rectify this situation.

The first hint is that ToM appears very early in ontogenetic development. Several studies have shown that sensitivity to eye contact is present even in newborns. The ability to gaze-follow is a bit slower to develop but usually appears after the first 6 months of life (Farroni et al. 2004a, 2004b, Farroni et al. 2004; Meltzoff and Brooks 2007). The second hint is that both eye contact and gaze following are of a clearly reflexive character (Senju and Johnson 2009a; Shepherd 2010). Even though they do interact with other cognitive processes their appearance and development is mostly predetermined and self-contained. The third hint is that manipulating visual attention can lead to hypnotic phenomena (Raz 2005; Caputo 2015). The key, however, to understanding the evolutionary origin of ToM is the realization that visual attention is not an innocuous activity but, rather, an activity centrally implicated in the handling of threat and danger (Chance 1967; Emery 2000).

\section{Evolutionary Beginnings}

Taking heed from these hints it is possible to conceptualize ToM in a completely new way. ${ }^{1}$ This new conceptualization is highly counterintuitive and builds on new findings from several research areas as well as reinterpretations of older findings. According to the present hypothesis ToM, and especially its eye contact and gaze-following components, evolved out of two ancient defensive reactions, namely tonic immobility and immobilization stress. Both reactions, evolutionary conserved in several species, are centrally implicated in the handling of stressful encounters and organically related to immobilization. This hypothesis has, to my knowledge, never been proposed before. $^{2}$ Although mostly speculative it synthesizes many of the findings in the field in a well-balanced and well-informed way.

Both of these reactions are common in immature individuals and have well-defined prosocial roles in the early development of several mammalian species. Furthermore, the handling that provokes both of these instinctive reactions, a combination of tactile and proprioceptive stimulation, is almost

\footnotetext{
${ }^{1}$ This perspective is not functionalist as most other theories in the field; it does not claim to have identified a new function of ToM. Instead, it claims to have identified its behavioral precursor and, by extension, part of its neurophysiological "history."

2 This idea, though it might strike some as outlandish, has partly been entertained before. Baron-Cohen (1995), while formulating his theory of an eye-direction-detector (EDD), discussed various gaze-following behaviors in lower animals, including those exhibited by prey animals; however, he did not elaborate on the evolutionary importance of TI or give it any theoretical weight in his subsequent work on ToM. In general, the importance of this primitive reflex has, hitherto, not been acknowledged in discussions of ToM.
} 
identical to that customarily used by humans in various nursing activities: embracing, holding down, inverting, breastfeeding, swaddling, carrying in a sling, tucking in, and rocking to sleep. Finally, an important correlate of both reactions is that they are often accompanied by altered states of mind, states reminiscent of the hypnotic trance.

\section{The Eye of the Tiger}

Threat detection is an important element in predator-prey relationships. When an animal senses danger, it must quickly gather relevant contextual information in order to protect itself: what constitutes the threat, where is it localized, how does it move, what intentions does it have? Perceptual vigilance is, therefore, an integral part of many defensive reactions. ${ }^{3}$

An example of such a defensive reaction is tonic immobility (TI). When escape from a predator is impossible many animals become suddenly immobilized in an attempt to appear dead (cf. "playing possum"). The innate releasing mechanism of TI is a combination of manual restraint and postural inversion, a handling which usually places the animal in a supine position. According to the prevailing view, TI hinders the predator from delivering a lethal bite or blow to its prey and, thus, gives it a last chance to survive and escape. This dramatic display comes about by a massive reduction of muscle tone, as well as a decrease in respiration/heart rate and body temperature, which leaves the animal in a state of flaccid paralysis. At the same time, it prepares the organism to withstand life-threatening trauma and heal its eventual injuries by the release of endogenous opioids, which confer a high degree of analgesia and anesthesia. Research has revealed that the control mechanism for this reflex is located in the phylogenetically most ancient parts of the mammalian brain, the brainstem, and operates by the release of the neurotransmitter acetylcholine. There is also a secondary involvement of the limbic system, in particular the hippocampus which emits distinct theta rhythms (Carli 1977; Thompson 1977; Porro and Carli 1988; Leite-Panissi et al. 2003; da Silva and Menescal-de-Oliveira 2006).

Animals that fall into TI often exhibit peculiar eye movements (e.g., intermittent blinking). In addition, they seem to be very vigilant of the eyes of their captor: they follow its gaze with their eyes and seem to adjust their immobility accordingly. This gaze-following tendency is so strong that artificial eyes (made of plastic and with no adhering head or body) have been used to potentiate the reaction in laboratory settings (Gallup 1977; Hennig 1977; Prestrude 1977: 36). This

\footnotetext{
${ }^{3}$ One example is the startle/orienting response. This response is the first-line of defense in a long chain of defensive behaviors. It is usually a reaction to a sudden noise but can also be elicited by visual or proprioceptive stimuli. Upon such stimulation, the animal abruptly ceases its ongoing activity and the eyes and ears scan the environment for threats. This audiovisual alerting is subserved by a special kind of brain activity: ponto-geniculo-occipital (PGO) waves, the same waves typical of REM sleep (Wu and Siegel 1990; Sanford et al. 1992). After the instantiation of this heightened awareness, the animal has the option of reacting in a number of ways depending on the situation: freeze, flight, or fight.
}

behavior is striking as the animal is otherwise completely immobilized and incapacitated.

Tonic immobility is very common among insects, amphibians, reptiles, and birds. Among mammals, it is somewhat rarer but, still, easily provocable in several species (e.g., guinea pigs, rabbits). It has even been reported, although in a highly weakened form, in primates. The pervasiveness of tonic immobility in the animal kingdom is a strong argument in favor of its adaptive value (Prestrude 1977; Ratner 1977; Hennig 1978; Klemm 2001). ${ }^{4}$ It is not only in animals, however, that we find such defensive reactions. As several authors have shown, similar reactions are involved in human behavior as well; their expression and effects may be more subtle than among other animals, but their existence is indisputable (Hoskovec and Svorad 1969; Suarez and Gallup 1976; Dixon 1998; Hall and Dawson 1998; Abrams et al. 2009; Levine 2010; Volchan et al. 2011). ${ }^{5}$

Most relevantly for our purposes, such reactions have also been observed in human children. Rousseau et al. (2014), for example, found that 8 out of 31 newborns showed significant immobilization reactions at birth. ${ }^{6}$ The main features of this

\footnotetext{
${ }^{4}$ This pervasiveness also explains why it has been given so many different names in the scientific literature, probably more than any other natural behavior or mechanism. Some of the alternative denotations are animal hypnosis, death-feigning, immobilization reflex, paroxysmal inhibition, thanatosis, cataplexy, submission reflex, freeze reaction, fright paralysis, and behavioral arrest.

${ }^{5}$ For example, several scholars have suggested that vasovagal syncope in humans may be a distant relative of TI (Porges 1995, 2011; Alboni et al. 2008; Alboni and Alboni 2014; Blanc and Benditt 2016). Vasovagal syncope, the familiar fainting spell, seems to be triggered by the same set of stimuli and share many of the same neurophysiological mechanisms as tonic immobility: strong emotions (e.g., fear, surprise), overexertion, pressure on the body, blood pressure fall, bradycardia, and loss of muscle tone.

There are also cases of full-blown tonic immobility reported in humans. The following excerpt from Guy Murchie's (1978: 227) book The Seven Mysteries of Life is an illustration of this. It recounts the fate of Major Redside while on a hunting expedition in India. Through an irony of fate he had the opportunity to experience how it feels to be overrun and subdued by a powerful predator and was lucky enough to survive and tell his tale:

[He had] stumbled when crossing a swift stream, dropping his cartridge belt into the water... now out of ammunition, he noticed a large tigress stalking him. Turning pale and sweating with fright, he began retreating... But it was already too late. The tigress charged, seized him by the shoulder and dragged him a quarter of a mile to where her three cubs were playing. As he recalled it afterward, Redside was amazed that his fear vanished as soon as the tigress caught him and he hardly noticed any pain while being dragged and intermittently mauled while the tigress played "cat and mouse" with him for perhaps an hour. He vividly remembered the sunshine and the trees and the look in the tigress's eyes as well as the intense "mental effort" and suspense whenever he managed to crawl away, only to be caught and dragged back each time while the cubs looked on and playfully tried to copy mama. He said that, even though he fully realized his extreme danger, his mind somehow remained "comparatively calm" and "without dread." He even told his rescuers, who shot the tigress just in time, that he regarded his ordeal as less fearful than "half an hour in a dentist's chair.'

${ }^{6}$ Whether such immobilization reactions continue in later stages of development, and if so to what extent, is presently unknown. There are, however, indications to this effect. A well-known, if anecdotal, example is offered by the "spaghetti legs" (decreased muscle tone in the extremities) and dazed look of many children when they are scolded and/or manhandled by adults.
} 
reaction were immobilization, frozen face, shallow breathing, and bradycardia. Interestingly, there seemed to be a positive relationship between this reaction and maternal prenatal stress. The authors theorized that this perinatal immobility is related to the defensive immobility exhibited by many reptiles and mammals in response to danger and threat (i.e., tonic immobility). ${ }^{7}$ These findings, though unexpected in the context of parent-child interactions, are well in line with basic understandings of this defense mechanism. Comparative developmental studies, for instance, have shown that TI is highly prevalent during infancy. Hence, the neotenous opossum is famous for its tendency to fall into tonic immobility. Similarly, rat pups and kittens are readily susceptible to tonic immobility and partly loose this facility as they grow up (Prestrude 1977; Whishaw et al. 1979; Rovee-Collier et al. 1991).

Tonic immobility is also believed to be the evolutionary progenitor of the transport reflex (aka dorsal immobility reflex), a widespread mammalian reflex directly implicated in neonatal care and infantile behavior. It consists of the instantaneous immobilization of the pups/kittens when their mother picks them up by the neck. This reflex is thought to facilitate their swift transportation while minimizing the risk of injury. Importantly, the immobilization of the pups/kittens is accompanied by an equally swift change in their state of mind. The new state of mind could best be described as a deep tranquilization or hypnotic trance. Thus, it seems as though evolution has reused the stereotypic behavior of prey, as they are carried away in their captor's jaws, in the service of childrearing (Prestrude 1977; Brewster and Leon 1980; Webster et al. 1981; Meyer et al. 1984; Yoshida et al. 2013; Esposito et al. 2015). ${ }^{8}$ Comparable reactions have been observed in human infants that are posturally inverted and

\footnotetext{
${ }^{7}$ Something that may help conceptualize this evolutionary step is the relative lack of manual handling (e.g., tactile stimulation, restraint, carrying, inversion) among reptiles, whether that be in sexual mating or childrearing practices. The main reason for this is that the extremities of reptiles lack the flexibility and dexterity necessary for such kind of contact. The only instance of such handling naturally available to reptiles is offered by predatorial encounters and is, hence, aversive in nature. For reptiles, in other words, manual handling is synonymous to victimization. But, as mammals evolved out of reptiles, manual handling became an increasingly common element in various forms of intraspecies relationships (including parent-child interactions). This newfound ability, however, came with "strings attached": manual handling continued to elicit defensive reactions (e.g., TI, IS, transport reflex) in those exposed to it, albeit in a transmuted form.

${ }^{8}$ The relationship between the two reactions is supported by the fact that they both share a number of constitutional features: proprioceptive and tactile stimulation of the spine/neck, flaccid paralysis of the body, cholinergic control of wakefulness/sleep and opioidergic modulation of noxious stimulation. These characteristics definitely connect the two phenomena as their simultaneous manifestation is hardly a coincidence; it is, rather, the mark of a profound neuroanatomical kinship (Prestrude 1977; Webster et al. 1981; Meyer et al. 1984).
}

rhythmically stimulated (Peiper 1963; Krojanker 1969; Vrugt and Pederson 1973).

\section{Trapped in Their Parents Bosom}

In recent years, the neuropeptide oxytocin has emerged as an important modulator of parent-child interactions. It is secreted from the child's posterior pituitary gland in connection to critical events (e.g., parturition, lactation) and also provided during nursing through the mother's milk. Oxytocin release has been shown to facilitate the development of parent-child attachment and also seems to play a role in sexual mating and pair bond formation. Part of this prosocial effect is accomplished by slowing down the maturation of the central nervous system thus prolonging the need of infant care (Nelson and Panksepp 1998; Feldman et al. 2007; Carter 2014). For this reason, it has been called the "love hormone."

Several studies have also shown that oxytocin increases visual attention by increasing both the number of fixations and the total gaze time directed to the eye region of other individuals. One way that oxytocin does this is by suppressing avoidance behaviors during potentially stressful encounters (Porges 2003; Guastella et al. 2008; Theodoridou et al. 2009; Domes et al. 2013). It is believed that this facilitates face recognition and emotional processing and promotes emotional bonding and interactional coordination between mother and infant.

However, the popular focus on oxytocin as the "love hormone" has obscured important facts from our consideration. There is a darker side to oxytocin. Animals exposed to immobilization stress (IS), an entrapment protocol, show marked elevations in their oxytocin levels, especially in plasma and spinal cord (Miaskowski et al. 1988; Ondrejcakova et al. 2010; Danevova et al. 2013). In experimental settings immobilization stress is produced by the forceful immobilization of an animal, either by manual restrain or by tightly strapping the animal (the animal is however not posturally inverted). ${ }^{9}$ In these studies, immobilization is the proprietary trigger of oxytocin release. For this reason, some researchers have claimed that coping with stressful encounters is the main function of oxytocin (McCarthy et al. 1991; Danevova et al. 2013).

One possible reason for the release of oxytocin in such circumstances is antinociception. Upon release, oxytocin moderates the intensity of the encounter by conferring a degree of anesthesia and analgesia (Uvnäs-Moberg 1998). Oxytocin also seems to modulate the activation of the amygdala and reduce the organism's responsiveness to threat stimuli (Kirsch et al. 2005). The connection to

\footnotetext{
${ }^{9}$ The same effect can also be achieved by placing the animal in a very tight box/cylinder.
} 
emotional pacification is also reinforced by oxytocin's relation to acetylcholine which itself has both trophic and (Danevova et al. 2013) pain modulating properties (Abelson et al. 2004; Dussor et al. 2004; Eisenach et al. 1996; Yang et al. 2008). ${ }^{10}$ Acetylcholine, for example, directly excites the paraventricular nucleus, a major site of oxytocin production and release (Honda et al., 1985). Oxytocin from the paraventricular nucleus quickly reaches various nerve centers in the brainstem - like the periaqueductal gray, raphe nuclei, and locus coeruleus - which are involved in the control of stress reactions, pain modulation, defensive behaviors, and REM/non-REM sleep (Uvnäs-Moberg et al. 2014). ${ }^{11}$

Immobilization stress is subject to interesting social modulation. Muroy et al. (2016), for example, found that the reaction has different social effects depending on whether the subjects experience the situation as safe or threatening. In a safe environment, immobilization stress led to increased social support-seeking behavior, decreased aggression, facilitated long-term sharing, and defined dominance ranks among rats while an unsafe environment (marked by predator odor) abolished all these benefits of immobilization. Importantly, it was only the safe environment that led to an increase of hypothalamic oxytocin signaling. Smith and Wang (2014), in their turn, showed that the anxiety-like behaviors and increased corticosterone levels following immobilization where absent in female voles allowed to recover in the presence of a male partner. This social buffering effect on stress was accompanied by increased oxytocin release in the paraventricular nucleus of the hypothalamus.

\section{Some Comments}

Although the present hypothesis may surprise some the general idea that primitive reflexes can have an important influence on human cognition and development is well attested, and generally accepted, in the scientific literature. An example of such a reflex is the diving reflex, which is involved in the control of respiration and heart rate (Porges 1995, 2011). Another is the fight-or-flight reflex,

\footnotetext{
${ }^{10}$ Given this realization, that oxytocin promotes defensive reactions, it is not surprising that oxytocin release occasionally also gives rise to aggressive behavior. An instance of this is the lowered threshold for aggressive behavior exhibited by many mammalian mothers during lactation, a period in which oxytocin levels are very high (Hahn-Holbrook et al. 2011).

${ }^{11}$ In addition to analgesia oxytocin also produces other effects. For example, several animal studies have shown that oxytocin produces transient amnesia, attenuating both the consolidation and retrieval of memory (Kovács and Telegdy 1982). Similar results have been found in later studies with humans (Heinrichs et al. 2004). This ability of oxytocin is interesting as it might offer a possible explanation for the ubiquitous amnesia that characterizes early childhood (Hayne 2004; Bauer 2007; Josselyn and Frankland 2012).
}

which is involved in functions as diverse as waking-up, interpersonal assertiveness, and sexual arousal (Selye 1936, 1955). It would almost be strange if other reflexes were not involved in this scheme as well. Tonic immobility, in particular, is a likely candidate. For many life forms, vertebrate as well as invertebrate, it constitutes one of their fundamental biobehavioral dispositions (the others being approach-or-avoidance, fight-or-flight, feed-and-breed, rest-and-digest). Therefore, it ought to have a major influence on the brain architecture and cognitive development of the human child.

Historically, TI and IS have been treated separately and seen as unrelated to each other. However, there are indications in the scientific literature of their potential intersection, at least among adult individuals. The area in which they seem to intersect most clearly is that of reproductive behavior. In many animals, defensive reactions are an important part of their reproductive behavior (Porges 2003). Among insects, for example, tonic immobility is commonly an element in the speciesspecific postures that accompany sexual courtship and intercourse (Spinner-Hansen et al. 2008). Equivalent behaviors, for example lordosis, have been observed in several mammalian species, from rat to elephant (Naggar and Komisaruk 1977; Smith et al. 1985). Similarly, the secretion of oxytocin suppresses avoidance behaviors and accompanies immobilization during courtship and mating in many mammals (McCarthy et al. 1991; Waldherr and Neumann 2007; Borrow and Cameron 2012; Danevova et al. 2013). Not surprisingly, one study found oxytocin involvement in the reproductive behavior of lordosis, a behavior that is believed to be related to TI (Gorzalka and Lester 1987).

Before proceeding to the next section a few comments are in place with regards to the role played by fear, the emotional trigger for both defensive reactions (albeit to differing degrees). While I do claim that the neural circuits controlling TI and IS have been evolutionary conserved and transferred to the human organism, critically influencing infantile behavior and cognitive development, I do not claim that human children live in a permanent state of fear or that their caregivers (especially their mothers) are the source of this fear. Instead I believe that the human organism, over the eons of evolutionary history, co-opted these neural circuits to its own conditions and needs, turning part of the vigilance and fear associated with them into more constructive uses (e.g. face recognition, sustained attention, emotional regulation). An important part in this development was played by the emergence of the human neocortex.

Still, there is no need to deny the obvious; fear is never far away when it comes to young children. Young children are easily scared and often resort to behaviors 
indicative of fear: frightful staring, crying, enuresis and encopresis, "spaghetti legs" (i.e., reduced muscle tone in the extremities), nightmares, and night terrors. Properly conceptualized these behaviors can help us understand important aspects of the parent-child interactional system, in particular its evolution. This is what the present hypothesis tries to do.

\section{Developmental Aspects}

Now that we have identified the evolutionary precursors of ToM, it is time to have a look at some of their developmental underpinnings. The presentation, however, is not going to be a comprehensive review of the literature but rather a selective primer intended to better contextualize the hypothesis.

\section{Neoteny and the Supine Position}

In recent times, we have become accustomed to hearing stories about the newly discovered abilities of human infants. Undoubtedly, a measure of celebration has been justified. Studying the psychology of prelinguistic children is extremely difficult and many ingenious methods had to be devised for this endeavor to bear fruit. Still, these advances should be seen in their proper context; we should not miss the forest for the one tree in front of us. The physical and neurological deficiencies of the human infant by far outweigh any rudimentary abilities it might have. These deficiencies circumscribe the early psychological development of the child. ${ }^{12}$

There is an evolutionary explanation for this situation. According to a number of scholars an important aspect in the evolution of Homo sapiens was the progressive infantilization or neoteny of the species, the pre-birth stage being retained into neonatal or adult life. While this may have handicapped the human child physically and behaviorally, it conferred to it an increased psychological plasticity and environmental adaptability, two very advantageous traits which eventually lead to the emergence of human culture (Gould 1980: 95-108;

\footnotetext{
${ }^{12}$ Fortunately this basic truth is reinstated from time to time. Here is the opinion of child psychologists Jean Mandler (1998: 300-301):

To close, it is possible to read this chapter as another version of the story of the super-competent infant, but such an interpretation would miss the point. Infants do not have the same skills as older children and adults. What they do have are all the elements out of which more complex processing will develop... [But] it still is true that infants are universal novices. The vast amount of learning that will accrue over the years will result in qualitative as well as quantitative changes in both behavior and thought.
}

Montagu 1988). ${ }^{13}$ Many attributes fall under the heading of neoteny. For instance, the hairlessness of the human child is a characteristic that in other mammals is only encountered in the fetal condition. Similarly, the axis of the human head is at right angles to the axis of its trunk which, once again, is a characteristic that in other mammals is only encountered in the fetal condition; this enables humans to walk upright and lie down in a supine position (Morris 1967: 32-34; Michel and Goodwin 1979).

The supine position is important for infants. Infants spend most of their time laying on their back in state of relative immobility. From this supine position, they observe the world, establish their first relationships, and perform most of their bodily functions. Frequently, infants are also manually restrained and posturally inverted by their caregivers as part of various nursing operations (e.g., embracing, breastfeeding, swaddling, carrying in a sling, tucking in, rocking to sleep), once again ending up in a supine position. In the literature on cognitive development, this predicament is usually either left uncommented or explained away with the help of circumstantial arguments: their bodies are immature, they are too heavy, they need rest etc. An exception to this rule is the work of Takeshita et al. (2009), one of the few treatises on the subject.

\footnotetext{
${ }^{13}$ In his book, The Naked Ape, zoologist Desmond Morris (1967: 32-34) gives a nice description of this phenomenon:

Put very simply, it is a process (called neoteny) by which certain juvenile or infantile characters are retained and prolonged into adult life... The way in which this process of neoteny helps the primate brain to grow and develop is best understood if we consider the unborn infant of a typical monkey. Before birth the brain of the monkey foetus increases rapidly in size and complexity. When the animal is born its brain has already attained seventy percent of its final adult size. The remaining thirty percent of growth is quickly completed in the first six months of life. Even a young chimpanzee completes its braingrowth within twelve months after birth. Our own species, by contrast, has at birth a brain which is only twenty-three percent of its final adult size. Rapid growth continues for a further six years after birth, and the whole growing process is not complete until about the twenty-third year of life...

We (or rather, our hunting ape ancestors) became infantile in certain ways, but not in others. The rates of development of our various properties got out of phase. While our reproductive systems raced ahead, our brain-growth dawdled behind. And so it was with various other parts of our makeup, some being greatly slowed down, others a little, and still others not at all. In other words, there was a process of differential infantilism. Once the trend was under way, natural selection would favour the slowing down of any parts of the animal's makeup that helped it to survive in its hostile and difficult new environment...

The fact that so many separate embryonic characteristics were potentially valuable to the hunting ape in his new role was the evolutionary breakthrough that he needed. In one neotenous stroke he was able to acquire both the brain he needed and the body to go with it. He could run vertically with his hands free to wield weapons, and at the same time he developed the brain that could develop the weapons. More than that, he not only became brainier at manipulating objects, but he also had a longer childhood during which he could learn from his parents and other adults. Infant monkeys and chimpanzees are playful, exploratory and inventive, but this phase dies quickly. [Human] infancy was, in these respects, extended right through into his sexually adult life. There was plenty of time to imitate and learn the special techniques that had been devised by previous generations. His weaknesses as a physical and instinctive hunter could be more than compensated for by his intelligence and his imitative abilities. He could be taught by his parents as no animal had ever been taught before.
} 
They contend that the supine position has profound developmental implications as it allows human infants abundant opportunities to engage in face-to-face interactions with their parents, a fact that helps them to develop various cognitive and prosocial abilities. ${ }^{14}$

The supine position, however, is far from innocuous. In most ethological studies, the supine position is described as a sign of defeat and submission (Grant 1963; Grant and Mackintosh 1963; Morris 1967; Dixon 1998). It is also the innate releasing mechanism of tonic immobility. Because of this signaling quality, and the dramatic neurophysiological changes that often accompany it, most reptiles and mammals usually try to avoid it. Still, human infants spend most of their early life in this position.

\section{Cholinergic Ascendance}

A large part of early development, including the emergence of ToM, takes place in a highly cholinergic environment, both on the inside and the outside. During pregnancy, the fetus is immersed in a highly cholinergic environment as evidenced by the fact that choline concentrations in amniotic fluid can be ten times higher than in maternal blood (Zeisel 2006). After birth, the infant is continually supplied with a high choline diet by way of breastfeeding. Human milk is rich in choline which pass into the infant's bloodstream and function as trophic factors for various cellular and neural structures (HolmesMcNarry et al. 1996; Ilcol et al. 2005). In fact, the demand for choline during pregnancy and lactation is so high that the mother's bodily stores are usually depleted. ${ }^{15}$

One of the main uses the human body makes of choline is to transform it into the neurotransmitter acetylcholine, a versatile neurotransmitter in the CNS. Acetylcholine plays a central role in cortical activation, behavioral inhibition, attention, memory, and learning processes (Hasselmo 2006; Kuo et al. 2007; Botly and de Rosa 2008). Acetylcholine is also the exclusive neurotransmitter of the parasympathetic nervous system, the part of the autonomic nervous system that is responsible for digestion, rest, recuperation, and reproduction (McCorry 2007). Finally, as seen in the previous section, acetylcholine is also the neurotransmitter underlying the tonic immobility reflex.

The bountiful supply of exogenous choline during the early years has its counterpart in a number of endogenous structures and circuits that utilize acetylcholine as their main neurotransmitter. These neural circuits (e.g., in the brainstem and midbrain) develop early in life and seem to have a guiding influence on the development and maturation of the rest of the brain (Lauder and Schambra 1999; Descarries et al. 2004; Arsikan et al. 2016).

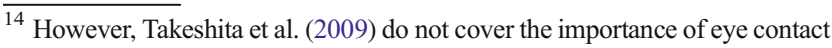
and gaze following in this context or its relationship to ToM. Nor do they implicate defensive reactions in it.

${ }^{15}$ This depletion accounts for some of the cognitive and emotional changes that afflict pregnant and lactating women.
}

\section{Paradoxical Sleep}

An important expression of this cholinergic dynamism is the early emergence and preponderance of REM sleep in human development. REM sleep is one of the stages of the human sleep cycle and is predicated on a pattern of cholinergic firing that starts in the brainstem (a subcortical region), spreads to the limbic region, and eventually activates parts of the cerebral cortex (Jouvet 1999; Pace-Schott and Hobson 2002; Datta and Maclean 2007).

REM sleep is so different from ordinary sleep that it prompted Michel Jouvet (1999), a pioneer in its study, to call it paradoxical sleep. For example, despite the appearance of inactivity, the brain is engaged in frenetic activity. This activity is evidenced electroencephalographically by a desynchronized EEG and experienced phenomenologically as dreaming. ${ }^{16}$ REM sleep is also characterized by postural atonia, a sudden loss of muscle tone throughout the body which effectively abolishes all body postures and prevents any sustained movement. This tonic inhibition differentiates REM sleep from the other sleep stages, which allow a certain range of motions. The only muscles still working during REM sleep are those performing life sustaining operations (heart, lungs) and, strangely, those of the eyes. The eyes, however, while still functioning behave eerily: they make rapid and jerky movements from side to side (Pace-Schott and Hobson 2002; Datta and Maclean 2007). ${ }^{17}$

Though the function of REM sleep remains elusive, converging evidence points to an organic relationship with the brain's visual system. Hence, it has been proposed that REM sleep stimulates the development of the visual system during infancy, informs the visual cortex about eye movements, and facilitates proper responses to environmental stimuli. Many of these functions are performed via its ponto-geniculo-occipital (PGO) waves. Not surprisingly, the incidence of REM sleep diminishes after the visual system has matured sufficiently (Roffwarg et al. 1966; Callaway et al. 1987; Herman et al. 1991). ${ }^{18}$ As for the eye movements themselves, some scholars believe they are expressions of visual activities (e.g., gaze shifts) that take place inside the dream imagery. This theory has found support in studies of people with REM sleep behavior disorder (RBD), an affliction in which the sleeping person tries to enact his dreams. It has been found that when they try to enact goal-oriented dreams they seem to adjust their eye and body movements in accordance with the dream action (Leclair-Visonneau et al. 2010).

REM sleep has a powerful influence on the early life of children. As most parents know newborns sleep most of the day; up to $17 \mathrm{~h}$ is not unusual. And when they do not sleep, they spend a lot of their waking time by the breast, half-asleep

\footnotetext{
${ }^{16}$ Dream mentation can be described as a form of dissociated thought: disorganized, detached, and delirious (Hartmann 1998; Hobson 1999).

${ }^{17}$ These eye movements are so central to this kind of sleep that they have given it its name, rapid eye movement sleep (Aserinsky and Kleitman 1953).

${ }^{18}$ For example, in kittens REM sleep declines sharply after their eyes open (Herman et al. 1991).
} 
and/or staring into their mother's eyes. Research has shown that newborns have no discrete sleep cycles and spend most of their sleeping time in a state resembling REM sleep. Slightly older babies spend around $50 \%$ of their sleeping time in REM. Most adults just spend around $20 \%$ of their sleeping time in REM sleep (Jouvet 1999; Blumberg 2013). ${ }^{19}$ An interesting observation is that as REM sleep diminishes with age the amount of time spent waking increases proportionally; additional wakefulness, hence, seems to "grow" out of a substrate of REM sleep. ${ }^{20}$

\section{REM Sleep, Mental Rehearsal, and Attachment}

An issue that is seldom addressed in connection with ToM is when human infants acquire this complex ability. The "when" in the preceding question is not meant in its diachronic sense (as in "When during a three year period") but in its synchronic sense (as in "When during the day"). This is a highly pertinent question as human infants spend most of the day sleeping. Unless we believe that human infants possess "superpowers" which they effectively employ during their few waking hours, we have to assume that ToM is acquired, at least in part, while asleep. ${ }^{21}$ This conjecture is strengthened by the fact that REM sleep seems to allow the operation of ToM, a remarkable fact given that it inactivates a number of other cognitive capacities, including logical reasoning, working memory, and selective attention (Pace-Schott 2001; Kahn and Hobson 2005; McNamara et al. 2007). How can we understand this peculiar situation?

More than 40 years ago, Michel Jouvet (1973) suggested an intriguing possibility. He claimed that the function of REM sleep is to periodically "reprogram" and "reboot" the human organism by promoting the rehearsal of important instinctual behaviors. Since then his claim has received considerable support (see Franklin and Zyphur 2005). ${ }^{22}$ For instance, investigators of animal learning have discovered that many behaviors critical for survival are learned during sleep. Examples of such behaviors are exploration in the rat, defensive maneuvers in the rabbit, and stalking in the cat (notice the connection to predatorprey relationships). The acquisition of these behaviors is subserved by a special type of brain activity, theta rhythms. The emission of such theta rhythms comes in two waves and is believed to facilitate learning and memory formation: the first emission is during the performance of the behavior itself, the

\footnotetext{
${ }^{19}$ After the first year of life, a number of neurological and endocrinologial changes take place which result in a decrease of REM sleep. After this, a stable sleep-wake cycle is established and the well-known sleep stages appear. For a more detailed discussion of infant sleep see Frank and Heller (2003) and Blumberg et al. (2005).

20 The idea that waking consciousness may phylogenetically and ontogenetically grow out of REM sleep is not taken out of thin air. It has, actually, been proposed by several researchers (Panksepp 1998: 125-143; Hobson 2009; Klemm 2011; Panksepp and Biven 2012: 377).

${ }^{21}$ And there is not really much pointing to the existence of such powers. See section on Neoteny and note 12 .

22 Modern sleep science has uncovered a number of functions for REM sleep which seem to support this contention: problem solving, memory consolidation, stress relief, threat rehearsal, theory of mind, and parent-child attachment.
}

second during REM sleep in something that looks like a "mental rehearsal" of the behavior (Winson 1972; Miller 1991). ${ }^{23}$

Similar phenomena have also been observed in humans. Emde and Koenig (1969), in their observational study of newborns, found that early smiling was almost exclusively connected to a particular organismic state, that of REM sleep and REM sleep drowsiness. Although this smiling response is far removed from the fully developed social smile, the authors speculated that they probably share a common neuropsychological foundation. This reflexive smiling can be seen as a ontogenetic adaptation whose purpose is to facilitate nursing and help establish the parent-child bond (Bjorklund 1987).

Zborowski and McNamara (1998) have proposed that REM sleep functions to promote nighttime physiological synchrony and daytime psychological attachment between mother and child and that it continues to have similar functions in the mature organism by promoting sexual mating and pair bond formation. ${ }^{24}$ More precisely, dreaming helps the child in its relating by constructing an internal representation or search space of the attachment object. The daytime search behaviors of the child are then guided by this internal working model and periodically activated in association with a 90-min daydreaming rhythm.

Antii Revonsuo (2000) has claimed that the main function of REM sleep is to process upsetting daily experiences and in so doing improve performance of various real-life tasks. Dreams accomplish this by rehearsing threat avoidance skills in the simulated environment of dream mentation. The ultimate goal of this rehearsal is to increase the adaptive capacity of the organism. This function is, supposedly, an endowment of our evolutionary past in which such dangers abounded in the environment and their successful evasion was a daily necessity.

Taken together, these studies can help us understand a rather puzzling ethological observation. Juveniles of several primate species, including humans, continue to sleep with their mother even though they have become fully detached from her during the day (Bowlby 1983: 184-192). Since this behavior has been evolutionarily conserved in so many species, there is a distinct possibility that it performs a vital function. What could this function be? As suggested above, the function of such a "sleeping relationship" could be to develop necessary survival and prosocial skills through offline cognitive processing triggered by physical proximity to the mother. ToM could be such a skill (Fonagy and Target 1997).

The most impressive evidence of REM sleeps importance for ToM, however, comes from studies of children with autism. As is well-known, a hallmark of this pathology is the lack of, or improper functioning, of ToM. Buckley et al. (2010) showed that

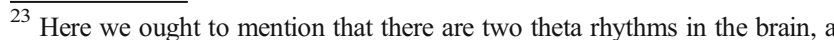
cortical and a hippocampal. Their mutual relationship is not fully clarified but a number of studies point to a coordinating, and hence primary, role of the hippocampal theta (Hasselmo 2005; Sirota et al. 2008).

${ }^{24}$ This initial proposal has now been corroborated in a number of studies (McNamara et al. 2001; McNamara et al. 2007; McNamara et al. 2011).
} 
autistic children have a much smaller REM sleep percentage of total sleep time than healthy controls. Likewise, other sleep disorders common to autistic children also seem to be related to perturbations of REM sleep (Devnani and Hedge 2015). Finally, Tessier et al. (2015) showed that neurotypical children and children with autism use different sleep-related brain networks to process and remember emotional faces; once again the significant difference was in the configuration of REM sleep. Thus, the evidence suggests that a relative dysfunction of REM sleep may underlie the pathogenesis of autism. ${ }^{25}$

\section{Pain and Attachment}

Another class of neurochemicals implicated in childhood development are the endogenous opioids. These substances have a special relationship to aversive experiences and are released in response to various physical (e.g., injury, heat) or social (e.g., separation, rejection) stimuli. Upon release, they help the organism withstand its challenge by conferring a degree of analgesia and also promote more adaptive responses by curbing the negative consequences of an overactive stress response. Since opioids also produce a sense of euphoria they additionally have a rewarding effect, especially if coupled with successful coping for example removing the source of injury or finding social consolation (Nelson and Panksepp 1998; Lieberman 2013; Valentino and van Bockstaele 2015).

The combined effect of analgesia and euphoria creates a motivational system critical for early survival. Whenever the infant is threatened or in pain its secretion of endogenous opioids rise (Hindmarsh et al. 1984; Leuschen et al. 1991). Nevertheless, if the challenge is serious the child's only way to cope is to solicit the help of its caregivers, something that provokes an intensive search behavior. ${ }^{26}$ If the child succeeds in its solicitation, its behavior is rewarded. This is so because by responding appropriately, usually through a combination of physical contact and feeding (e.g., postural inversion and placement by the breast), the mother increases the child's opioid stimulation. This is done partly through tactile stimulation, which is known to release endogenous opioids, and partly by milk infusion, which is a rich source of endogenous opioids (Nelson and Panksepp 1998; Zanardo et al. 2001). If the parental response is not prompt and appropriate, however, the child experiences separation distress which further exacerbates its agonizing state (Bowlby 1983; Lohaus et al. 2001).

\footnotetext{
${ }^{25}$ This deficit in REM sleep could also help explain the frequent seizures observed in autistic children. This is so because REM sleep deprivation is a known trigger of epileptic seizures (Cohen and Dement 1970; Hrncic et al. 2013). One way through which REM sleep deprivation accomplishes this is by significantly increasing cerebral excitability (Owen and Bliss 1970; Nykamp et al. 1998).

${ }^{26}$ Harry Harlow (1963: 17-18), for example, showed that the number of visual fixations of the mother by the infant are dramatically increased by their spatial separation.
}

Thus, for the child, successful coping reinforces contact seeking and relationship building with its caregivers.

Several scholars have pointed to the evolutionary significance of the endogenous opioids, a role in many ways similar to that of oxytocin. Nelson and Panksepp (1998: 439), for example, claim that "ancient pain mechanisms may have provided the neural substrates for the evolution of separation distress mechanisms." By extension, they may also have provided a template for the development of various prosocial behaviors aimed at ameliorating the pain of separation, including that of parent-child attachment (Kalin et al. 1995; Weller and Feldman 2003; Lieberman 2013).

\section{Eye Movements and Dissociative Phenomena}

Studies have shown that the daytime thinking of infants and young children is dominated by a special kind of brain activity, theta rhythms. As children grow up, however, theta rhythms are gradually crowded out of the brain by other types of brainwaves (Orekhova et al. 2006; Jones et al. 2015). One of the last vestiges of theta rhythms in the adult organism is REM sleep. REM sleep abounds in both cortical and hippocampal theta rhythms (Cantero et al. 2003). In adults, when present, theta rhythms have been associated with pleasurable feelings, drowsiness, creativity and meditative states (Schacter 1977; Gruzeler 1998; Jensen et al. 2015).

Theta rhythms are mainly produced by the hippocampus and some parts of the cerebral cortex (Cantero et al. 2003; Gray and McNaughton 2008). In experimental animals, this type of brain activity is connected to either active exploration or to motionless alertness. There seems to be a division of frequencies in this regard. Active behavior is associated with the higher range of theta frequencies $(7-10 \mathrm{~Hz})$, while motionless alertness with the lower range $(6-7 \mathrm{~Hz})$. Interestingly, motionless alertness seems to be predicated on cholinergic neurotransmission and consistently evoked by the threatening presence of a predator and accompanied by visual vigilance (Kramis et al. 1975; Sainsbury et al. 1987; Boucetta et al. 2014: 4725).

Motionless alertness is common in human infants. Perhaps the most dramatic example of this is the phenomenon of staring spells (Carmant et al. 1996; Park et al. 2015; Rosenow et al. 1998). As every parent knows, infants have a tendency to become highly absorbed by visual stimuli, especially faces and their eyes, and can stare at them for prolonged periods of time. This behavior can be so frequent and marked that it is often misjudged for epileptic seizures leading alarmed parents to rush to the nearest emergency room for medical assistance. The outcome of these visits is usually benign as the behavior is non-pathological.

As suggested above, there seems to be a special relationship between eye movements and altered states of mind. This relationship has wide-ranging consequences. For example, sustained attention coupled with monotonous stimulation can trigger various dissociative phenomena, from everyday mind wandering (Wegner 1997; Biever and Karinch 2012) 
and ordinary drowsiness (Thiffault and Bergeron 2003; Sallinen et al. 2004) to highway hypnosis (Miles 1929; Williams 1963) and perceptual hallucinations (Caputo 2015). ${ }^{27}$ An iconic example of this relationship is offered by hypnosis. ${ }^{28} \mathrm{I}$ believe this relationship is of great importance for a proper understanding of the phenomenon of ToM.

\footnotetext{
${ }^{27}$ There are less mundane, and more bizarre, examples of the relationship between eye movements and altered states of consciousness. We have already mentioned one of them, REM sleep. Eye movement desensitization and reprocessing (EMDR) is another example of the peculiar relationship between eye movements and altered states of mind. EMDR is an emergency method used to treat traumatized individuals (Shapiro 1989). Although controversial when it first appeared on the scene it is now corroborated by considerable research and, therefore, increasingly accepted. Its modus operandi is the performance of various eye movement exercises which confer a tranquilizing effect and may lead to a quick remission from disorders such as PTSD (Wilson et al. 1996; Barrowcliff et al. 2004). A noteworthy difference between these two cases is that the eye movements of REM sleep lead into dissociation, while those of EDTA lead out of dissociation.

${ }^{28}$ Hypnosis can be seen as the transfer of one person's intentions and plans to a receptive subject who behaviorally executes them. Hypnosis is, in this regard, a highly asymmetrical power relationship: the hypnotist is the dominant part, while the hypnotized person is the submissive one. The "hold" that a skilled hypnotist can have on his subject makes one inadvertently think of the relationship between predator and prey (cf. the ethological examples throughout the text).
}

Even though hypnosis remains a rather elusive phenomenon it is becoming increasingly clear that it has a special relationship to visual attention and eye movements. Thus, for instance, highly hypnotizable subjects have been shown to exhibit special eye movement patterns (Tebécis and Provins 1975). Another study came to the conclusion that the only neurophysiological correlate that is consistently related to hypnosis, and can hence stand in as its operational definition, is the "trance stare." This stare into the void, typical of hypnotized subjects, consists of objective and measurable changes in the optokinetic reflex, the pupillary reflex, and of programming a saccade to a single target (Kallio et al. 2011). Not surprisingly, the prevailing scientific explanation of hypnosis - how it comes about and what it stands for-is based on this premise: the narrowing down and focusing of attention (Crawford 1994, 2001; Gruzeler 1998).

Hypnosis, however, is not only accompanied by various eye movements but also by a tactical surrender and conditioned inhibition of the subject. This state is experienced as a mixture of apprehension and relaxation, and is often accompanied by various degrees of paralysis. Once again this reaction is well attested in the literature on hypnotism (Forrest 1999). Trying to achieve deep relaxation is often both a means to an end and an end in itself in many hypnotic sessions. The following is an example of a hypnotic induction taken from the repertoire of famous hypnotist Franz Polgar (1951: 31):

You are completely comfortable, now. Your whole body is relaxed. You have no feeling of tension, anywhere. Your eyes are getting tired and you want to close them. They are getting so tired, so very tired. You are tired. In a minute you will not be able to keep them open. Your arms are getting heavy. Your legs are getting heavy. You are completely relaxed know... You are getting so drowsy...

Finally, hypnosis also confers a measure of analgesia and anesthesia (Elkins et al. 2007; Stoelb et al. 2009). Actually, this is one of hypnosis oldest, and historically most significant, applications. In the nineteenth century, hypnosis was mainly used as a medical device in the treatment of physical ailments and not like today as a psychotherapeutic or entertainment technique. Famous examples of this use are John Elliotson's and James Esdaile's surgical operations under hypnosis and without the use of anesthesia (Forrest 1999).

The preceding discussion raises some pertinent question: What is the relationship of hypnosis to sleep? Despite appearances hypnosis does not seem to be related to sleep (Clark Hull 1933). However, hypnosis shows considerable similarities to REM sleep, a fact noticed and commented by several researchers (Brady and Rosner 1966; Barrett 1979; Gabel 1988; Hobson 1999: 242-256). Like hypnosis, REM sleep is characterized by an activated EEG pattern and is, hence, closer to wakefulness that to sleep. This brain activation is experienced, on the phenomenological level, as the experience of dreaming.

\section{Supportive Evidence}

With a hypothesis on the origins of ToM in place, we next turn our attention to its evidentiary basis. Is there any evidence, direct and indirect, in support of its various claims? I believe there is and that it is sufficiently robust to point the way from a mere analogy to an evolutionary homology. In what follows, I will present this evidence as well as address some unattended issues.

\section{Immobilization and Eye Contact}

The present hypothesis claims that immobilization reactions (whether TI or IS) during early childhood facilitate eye contact and gaze following. Is there any evidence for this in human children? To begin with, there is plenty of anecdotal evidence. Human children like to be carried, hugged, and cuddled and all these behaviors can, actually if counterintuitively, be seen as various forms of manual restraint and immobilization. ${ }^{29}$ These behaviors are seen as instrumental in the development of children's cognitive and prosocial abilities, an effect which is thought to be mediated, at least in part, by the increased incidence of face-to-face communication that they enable. The importance of such physical contact has become part of presentday folk psychology and also incorporated in many nursing best practices (Montagu 1986; Ardiel and Rankin 2010). ${ }^{30}$

\footnotetext{
(continued)

How about the hypnotizability of young children? The issue of children's hypnotizability is controversial and has been hotly debated in the past. Due to the difficulty of hypnotizing young children with the help of standard induction procedures it has traditionally been assumed that they have low hypnotizability. This view has recently been challenged by new findings, both clinical and experimental, that show that young children's relationship to hypnosis is of a more constitutional character (i.e., unlearned and self-generated) than that of adults and, therefore, difficult to ascertain with the help of standard techniques and measurements. The new consensus that is emerging is, instead, that young children's hypnotizability is on a par with, if not higher, than that adults (Kohen and Olness 2012).

${ }^{29}$ Older children, that have learned to crawl or walk also like to be "scared" by their parents. This particular kind of play usually contains behaviors that are reminiscent of those found in predator-prey interactions: pursuit, capture, subdual, surrender, manual restraint, and postural inversion. During these interactions the children's vocalizations alternate between screams of panic and uncontrollable laughter. Here it is worth mentioning that some authors view laughter as a perverted fright reaction that in human evolution attained an independent communicative status (Morris 1967: 116-125).

${ }^{30}$ The following, for example, is advice offered by a nursing textbook to parents on how to promote healthy parent-child attachment (Leifer 2012: 243, my italics). Compare its suggestions to the ethological examples offered throughout this text:

Encourage eye-to-eye contact. Advice parent to position newborn so they can look at each other. Optimum gazing distance for newborns is 7 to 10 inches.... Encourage touch; parent's touch usually progresses from fingertip exploration to open palm caress; the mother may then enfold the baby in her arms; this is followed by stroking newborn, picking up newborn, and holding newborn close; the newborn will become quiet and relaxed; touch facilitates attachment... Encourage cuddling the newborn; holding the newborn close and feeling the warmth initiates a positive experience for the mother; it is selfquieting and consoling to the newborn.
} 
Interestingly, as all parents know, this receptivity to manual restraint seems to wane as a function of the child's increasing physical competence and sense of self; older children and adults do not tolerate comparable levels of manual handling and restraint (Camras et al. 2005: 290). This is important to keep in mind as physical restraint of older children, when the critical "socialization window" has greatly diminished or even closed, may be counterproductive, and potentially damaging, as a means of achieving empathy and communication between parents and children. A reason for this may be that older children have more developed sympathetic nervous systems and, hence, are more easily aroused and stressed than infants and toddlers (Slotkin et al. 1990; Quingley and Stifter 2006; Gunnar and Quevedo 2007).

When it comes to studies directly testing the facilitating effect of immobilization on eye contact and gaze following the evidence is more scant. There are many possible reasons for this. One reason is epistemological. For various reasons, studies of this kind have not been deemed relevant or necessary. Another reason for this scarcity is ethical. Forcefully immobilizing human infants is, for most intents and purposes, unacceptable to both parents and researchers. Despite this, however, there are a number of studies that offer tentative support of this relationship.

In a qualitative study, Svendsen et al. (2015) observed the body movements and facial expressions of children immobilized during peripheral vein cannulation. They identified three broad response patterns: protest, escape, and endurance. Closer scrutiny revealed, among other things, that children in the two first categories showed signs of fear and panic during the procedure and generally avoided eye contact with the nursing staff, while those in the endurance category showed signs of paralysis and dissociation but did not avoid eye contact with the nursing staff.

Camras et al. (2005), in a cross-cultural study, investigated the facial expressions of infants subjected to arm restraint, an experimental procedure in which the mothers partially immobilize their children. This procedure is thought to increase children's emotional reactivity and allow the observation of self-soothing and comfortseeking behaviors. They found that arm restraint consistently lead to an increase of various facial expressions, irrespective of cultural background. Moscardino and Axia (2006: 66) corroborated these findings and also revealed that while at 2 months of age self-soothing and comfort-seeking behaviors were marginal and unspecific a new pattern seemed to emerge at 6 months. At that age "infants exhibiting higher levels of distress were more likely to orient their attention towards their mothers and less likely to look at objects in the environment during arm restrain".
Finally, Porter et al. (1998) studied the effect of handling and immobilization on pain reactivity in healthy full-term infants. They found that infants that had been handled and immobilized as a result of common nursing activities displayed higher physical arousal and more facial expressions following a heel stick (a classical noxious stimuli) than those who had not been subjected to this treatment.

Although the above studies are heterogeneous methodologically, and their results preliminary, their findings lend support to the present hypothesis. It is possible that immobilization, whether due to constitutional factors (i.e., TI, IS) or to environmental influences (e.g., nursing), has the accidental effect of potentiating the facial expressivity and eye-contact seeking of human infants. Using a metaphor we could say that by being immobilized infants wear their hearts on their faces. ${ }^{31}$ If so, this was an "accident" of the outmost phylogenetic and ontogenetic importance as it enabled an increased incidence of face-to-face communication and, by extension, the emergence of quintessentially human capacities (e.g., theory of mind, attachment, empathy, forethought). One possible way this came to pass is by the innervation of the human face by the vagus nerve, a cholinergic nerve which is activated by the stimulation of pressure receptors on the body and has both inhibitory and expressive qualities (Field and Diego 2008; Porges 2011). Another by the workings of oxytocin which is released in response to stimulation of pressure and heat receptors and promotes eye contact and gaze following (Carter 2014; Uvnäs-Moberg et al. 2014).

\section{Childrearing Practices and Immobilization}

If the present hypothesis has any merit to it, it should show some correspondence to how children have been handled over the ages. Although a thorough review of the matter falls outside the scope of this presentation, it is fair to say that infant immobilization has figured prominently in the history of human childrearing practices, whether in hunter-gatherer, agrarian or modern societies (Lipton et al. 1965; Frenken 2011, 2012). The ways in which infants have been immobilized in order to facilitate their care and the work of the adults are numerous: holding in the bosom, swaddling, carrying in a sling, putting in a cradleboard etc. Although some of these practices have fallen out of favor today, it is possible that they played an important role in human evolution.

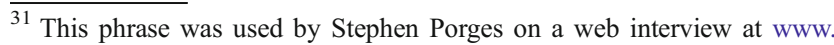
nicabm.com on February 6, 2017.
} 
Looking closer at swaddling, perhaps the most emblematic of all immobilization practices, further confirmatory evidence emerges. This childrearing practice, which was near-universal until a century ago, consists of wrapping a child's body up to the neck in cloth thereby immobilizing it and confining it to a mostly supine position. The classical study by Lipton et al. (1965), which used a much milder form of swaddling than the historical forms, found that the practice had two main effects: the babies became motorically calm (i.e., less aroused) and they slept more. Newer studies have confirmed these results and also found that swaddling, especially in preterm infants, leads to improved neuromuscular development, less physiologic distress, better motor organization, and more self-regulatory ability (Van Sleuwen et al. 2007). ${ }^{32}$ Even more interesting is the finding that swaddling enhances the incidence of REM sleep in infants and has an inhibitory effect on spontaneous arousals during sleep (Gerard et al. 2002; Franco et al. 2005). ${ }^{33}$ These findings are well in line with postulates of the present hypothesis. It should be mentioned, though, that swaddling has also been found to have certain adverse effects. For example, it may increase the risk of developing hip dysplasia (Van Sleuwen et al. 2007).

\section{Eye Contact and Threat}

Figuring out the intentions of another individual is one of ToM's main functions. Any theory that purports to explain its origins should have something to say about it. How does defensive immobilization contribute to this delicate task? As it turns out it, its contribution is fundamental. Despite the appearance of inactivity, a captured animal retains a high degree of visual vigilance. This is a purposeful behavior. An animal that has been caught in the claws of a predator needs to know, at every moment, what its captor's next move will be, what his intentions are. If the victim can gather such information successfully, it has

\footnotetext{
$\overline{32}$ Some studies have even suggested that swaddling may lessen the incidence of sudden infant death syndrome (SIDS) by promoting a favorable supine position. The issue of swaddling's effect on SIDS, however, is far from settled and actually quite controversial. While some studies show that swaddling may protect against it (Richardson et al. 2009) others show that it may increase it (Pease et al. 2016). The verdict is, hence, still out. I personally believe that swaddling may have played a certain role in human evolution by further promoting the supine position in infants (which is natural to them anyway), and that irrespective of its effects on SIDS.

${ }^{33}$ It seems that swaddling inhibits "each step from sighs through startles to full arousal in the arousal pathway" (Van Sleuwen et al. 2007: 1099). Such spontaneous arousals are driven by aminergic neurotransmission and can, in older children, escalate into a full-blown night-terror, a dramatic reaction which is seen by many sleep experts as a runaway instance of the fight-or-flight reflex (Ferber 2006; Schenck 2008)
}

a better chance to escape and survive. And one of the best sources of such information is the eye movements of the predator. This fact, attested in the literature on predatorprey relationships, adds considerable depth to the present argument as it directly addresses the issue of intentionality. And it points to a plausible evolutionary scenario: the intentionality detector inherent in TI and IS was, through successive stages of mammalian evolution, transferred to human cognition, and became the founding stone on which ToM was built.

But is there any human evidence, beyond the ethological studies cited, to support such a contention? Several investigations have pointed to a possible relationship between ToM and threat perception. Connolly et al. (2016), for example, showed that when evaluating the dangerousness or predaticity of various animals the human brain relies on an area called the superior temporal sulcus. As pointed out in the introduction, this area is centrally implicated in the control of both face recognition and mindreading. In other words, threat perception and ToM are subserved by the same neural circuitry.

The connection of the superior temporal sulcus to tonic immobility is strengthened by other findings as well. Schultz et al. (2005) found that the superior temporal sulcus plays an important role in the automatic identification of animate entities (i.e., the ascription of animacy) by responding directly to the perceived correlation between two moving objects. Of course, such a discriminatory ability is of paramount importance in predator-prey relationships where it is imperative, at every moment, to know if the enemy is moving towards or away from oneself.

Similarly, studies have shown that the superior colliculus, another structure involved in the control of ToM, is implicated in the visual detection and recognition of threatening stimuli such as snakes and faces with emotional expressions (Maior et al. 2012). This overlap in function is most pronounced during infancy, a finding also in line with the present hypothesis as TI and IS are also more pronounced in immature individuals. Interestingly, the superior colliculus has also been implicated in the control of both the eye movements and the circadian timing of REM sleep (Doricchi et al. 1993; Miller et al. 1998, 1999).

Impressive evidence also comes from studies of the orienting response, an emergency reaction to unexpected stimuli. Here, several studies have pointed to a rather unexpected finding: the orienting response in humans, though not a social behavior per se, is directly related to the faculty of ToM. The two reactions are actually subserved by the same neural circuits (Corbetta et al. 2008). This makes perfect sense in light of the present hypothesis as the orienting response is a well-known 
defensive maneuver, the first in line of the mammalian defensive cascade. ${ }^{34}$

Much of this threat perception and intention detection is done with the help of the eyes, through eye contact and gaze following. ${ }^{35}$ Eye contact, however, is in most mammalian species a sign of assertion and imminent aggression. For this reason, other than in aggressive encounters and predatoryprey relations, direct eye contact is a relatively rare occurrence in the animal kingdom. Whenever it occurs it is necessarily accompanied by appeasement displays (Morris 1967: 163165; Dixon 1998). Humans are a blatant exception to this near-rule. How did humans develop a knack for this behavior, most strikingly evidenced by the almost compulsive eyecontact seeking of infants? A possibility is that a hypertrophy in the eye contact seeking and gaze-following components of TI and IS, along with an enlargement of the prefrontal cortex, made this behavioral change possible (more on this later).

However, not all humans like eye contact to the same degree. Autistic people, in particular, have inborn difficulties with eye contact, difficulties that go well beyond personal idiosyncrasies and cultural conventions. For such people eye contact is a highly distracting and distressing event, one which

\footnotetext{
${ }^{34}$ The defensive cascade is a purported set of defensive maneuvers that usually occur in close temporal proximity to each other and consist of the following reflexive reactions: startle, orienting, freeze, flight, fight or faint (tonic immobility). This behavioral sequence has been observed in many different species (Gray and McNaughton 2008; Kozlowska et al. 2015; Löw et al. 2015). Since these behaviors form a functional hierarchy they have different "overriding" powers in relation to each other. Tonic immobility has the "last word" in this cascade and, hence, overrides all other responses. It is a terminal response and the animal that has fallen into it is unable to do anything else for a considerable time.

${ }^{35}$ Extrapolating from the above studies, and adding a few more, it is even possible to reconstruct the neural circuitry connecting intentional attributions to threat perception. Studies have shown that the threat perception performed by the amygdala, and relayed to the rest of the brain, is heavily dependent on visual information, face processing and eye contact in primates (Wada 1961; Nichols and Champness 1971; Young et al. 1995; LeDoux 1996; Jongen-Relo and Amaral 1998; Emery 2000). The coordination of these eye movements (e.g., horizontal gaze, saccades) and the production of REMs is controlled by two distinct neural networks: one located in the brainstem and including mostly cholinergic areas like the pedunculopontine nucleus, the abducens nucleus, the paraabducens nucleus, and the medial longitudinal fasciculus (Leigh and Zee 1999; Bae et al. 2013), and one located in the prefrontal cortex and centered on the so-called frontal eye fields (Vernet et al. 2014). Furthermore, several studies have shown that the motionless alertness typical of apprehensive animals is undergirded by a special kind of neural activity in the hippocampus, namely theta rhythms (Kramis et al. 1975; Sainsbury et al. 1987; Gray and McNaughton 2008). Finally, release of oxytocin from the paraventricular nucleus is part of the stress response and has been shown to enhance face processing and eye-contact (Guastella et al. 2008; Domes et al. 2013; Auyeung et al. 2015). Taken together these studies suggest the presence of a putative neural circuit that includes the amygdala, the hippocampus, the superior temporal sulcus, the superior colliculus, the frontal eye fields, the paraventricular nucleus, and the brainstem. Since the main route of information from the eyes, and about the eyes, to the rest of the brain passes through the central nucleus of the amygdala this circuit is probably centered on the amygdala. Functioning as a "gatekeeper," the amygdala attaches emotional valence to various perceptual stimuli and subsequently signals the brainstem to initiate the appropriate emotional response (e.g., fight-or-flight, freeze, tonic immobility).
}

they habitually avoid (Baron-Cohen et al. 1997; Senju and Johnson 2009b). More than that, recent research has shown that, like in many mammalian species, autistic persons experience eye contact as a direct threat (Dalton et al., 2005), a threat that leads to an immediate and disturbing activation of the sympathetic nervous system. It is as if the neural circuitry that makes eye contact non-threatening, and even attractive, for the majority of people is defective or absent in the case of autistic children. ${ }^{36}$

\section{Temperament and Inhibitory Control}

Tonic immobility is the main inhibitory reflex of the mammalian defensive cascade and is predicated on cholinergic neurotransmission instead of aminergic neurotransmission (Thompson 1977; Klemm 2001; Kozlowska et al. 2015; Löw et al. 2015). ${ }^{37}$ As such, it is both antithetical to the fight-or-flight reflex and parasympathetic in character. ${ }^{38}$ If, as hypothesized, the faculty of ToM evolved from the TI reflex it should exhibit traces of this inhibitory character. Are there any such traces?

Considerable support comes from studies that have looked at the relationship of ToM to higher order functions. Several studies have shown that inhibitory control, the ability to suppress or moderate prepotent responses, is intimately related to the faculty of ToM. Carlson and Moses (2001), for example, showed that performance in tasks requiring a novel response in the face of a conflicting and prepotent response, as well as tasks requiring the delay of a prepotent response, were significantly related to ToM. Chasiotis et al. (2006), in a large international study, found a culture-independent relationship between conflict inhibition and false belief understanding among preschool children. Taken together, these findings show that inhibitory control is a crucial enabling factor in the development and function of ToM.

Support also comes from studies of the relationship between temperament and cognitive development. It is wellknown that temperamental differences have a direct bearing on parent-child interactions and can even influence the attachment process (Thomas and Chess 1977; Kagan 1982). One

\footnotetext{
${ }^{36}$ Autistic children have trouble handling other kinds of sensory stimuli as well (e.g., auditory, tactile). Especially if presented simultaneously across several sensory modalities, which is often the case in face-to-face social intercourse, they may overload their processing capacity and lead to a cognitive and behavioral "shut-down." Studies have shown that this sensory overresponsivity (SOR) is predicated on a hyperactivity in areas related to primary sensory processing, emotional regulation, and response to threat (Green et al. 2015).

${ }^{37}$ A similar, but less pronounced, inhibitory role is played by the freeze reflex, which seems to be driven by GABAergic and cholinergic neurotransmission (Power and McGaugh 2002; Jhou 2005).

${ }^{38}$ Despite its reflexive nature TI is not easy to fit into the sympatheticparasympathetic dichotomy. There are, for instance, conflicting results concerning heart function with some studies finding increases in heart rate and others finding decreases (Davie et al. 1993; Valance et al. 2008; Giannico et al. 2014). On account of its opposition to the fight-or-flight reflex, its cholinergic neurotransmission and general passivity I prefer to place it on the parasympathetic side.
} 
theory that has made specific predictions about this relationship, and garnered considerable support, is the emotional reactivity hypothesis (Hare 2007). ${ }^{39}$ According to this theory children with less reactive temperaments will reach certain milestones of cognitive development, including ToM, more quickly. Wellman et al. (2011), for example, reported longitudinal data showing that a temperament characterized by a lack of aggressiveness, a shy-withdrawn stance to social interaction and social-perceptual sensitivity at 3 years of age was predictive of a more advanced ToM understanding 2 years later. Similarly, Mink et al. (2014) found that children with a less reactive and more observant temperament had more sophisticated ToM capabilities. This relationship also had a high predictive value with shy temperament at 18 months predicting better mindreading skills at 3 years of age.

\section{The Lessons of Domestication}

A remarkable fact is that some domesticated animals seem to have cognitive abilities that rival, and occasionally even surpass, those of primates. Dogs, for example, are unusually skilled at reading human social and communicative behavior: they readily follow pointing gestures, seek eye contact, gaze follow, and even show rudimentary forms of ToM (Miklosi et al. 1998; Hare and Tomasello 2005). These findings, which have perplexed scientists for a long time, are now beginning to be understood within a unified framework.

Domestication induces a number of critical changes in the biology and ethology of animals (Wilkins et al. 2014). One way of understanding these changes is to realize that domestication leads to a reduction in aggression, and a corresponding increase in docility, relative to the animal's wild-type forebears. Studies have shown that this change is mediated by a downregulation in the activity of the sympathetic nervous system, the system which controls the fight-or-flight reflex. Domesticated foxes, for example, exhibit reduced adrenal gland size and have a three- to fivefold reduction in both basal and stress-induced blood cortisol levels (Osadschuk 1997; Trut et al. 2009). Similarly, domesticated rats and guinea pigs have both reduced adrenal gland size and reduced blood corticosterone levels (Künzl and Sachser 1999; Albert et al. 2008). ${ }^{40}$

\footnotetext{
${ }^{39}$ This theory has some intriguing similarities to the affective reactivity model proposed by Jeffrey Alan Grey (1994). See also Gray and McNaughton (2008).

${ }^{40}$ These insights from domestication studies resonate with some ethological observations in monkeys. A number of studies have found impressive sociocognitive abilities - for example, eye contact and gaze following - in stumptailed macaques and orangutans, animals that are more distantly related to humans than chimpanzees. It is hypothesized that these abilities may have developed as a result of these animal's gentle and relaxed manner of interacting with each other, a way of being that is in stark contrast to the more aggressive attitude of chimpanzees (de Waal 1989; Brothers et al. 1990; Brothers and Ring 1993; Emery 2000).
}

Another way of understanding the prosocial changes brought about by domestication is by realizing that selective breading for tameness tends to produce neotenous changes in the offspring, both in the sense of growth retardation and in the sense of pedomorphic features. For example, domesticated foxes exhibit a growth retardation which affords them a considerably longer "socialization window" during which they can learn to interact with their human caretakers in a relaxed manner (Belyaev 1984; Trut et al. 2004).

These two ways of understanding the effects of domestication are, furthermore, intrinsically related as immature individuals are by default less aggressive than their grown-up counterparts. The enlarged window of socialization during infancy in domesticated animals is, hence, to a large extent predicated on the prolonged immaturity of their hypothalamic-pituitaryadrenal system which prevents them from resorting to fearful reactivity as often, and as forcefully, as their wild-type kin.

While the above domestication studies did not directly address the involvement of inhibitory mechanisms in the animal's behavior patterns, it is not difficult to imagine their underlying presence. The animals were kept captive, lived in enclosed spaces, and subjected to manual restraint, all proprietary triggers of defensive immobilization reactions. ${ }^{41}$ It is, therefore, not unreasonable to assume that the reduction in sympathetic drive observed in these animals, an unmistaken mark of domestication, was also accompanied by a corresponding increase in the activity of counterbalancing mechanisms, like those of TI and IS. After all, the essence of tameness is that an animal readily yields to its master. This tipping of the scales in favor of passive defenses (as opposed to aggressive defenses) may actually have enabled the evolution of the devotional tie between dogs and humans. ${ }^{42}$

According to several scholars this curbing of the aggressive drive, a kind of self-domestication, also played an important role in human evolution (Morris 1967; Eccles 1989; Hare 2007; Hare et al. 2012). Biological, environmental, and

\footnotetext{
41 The following is an account of the domestication procedure by Trut et al. (2004: 645):

The main task at this stage of selection was eliminating defensive reactions to humans [the authors use a different terminology but are referring to aggressive behaviors]... the animals in the selected population were subjected to more intensive contacts with humans than in usual practice. During these contacts, the pups were subjected to a number of tests: the experimenter attempted to hand feed, stroke or handle them. This type of human-animal communication continued for the first three to four months of life of the animals. As a result, the emotionally negative defensive reactions to humans in these foxes weakened, disappeared or, in some of the animals, emotionally positive reactions were formed. The foxes that retained aggressive-fearful reactions to humans in spite of the 3-month period of human contacts with them, were eliminated by selection from the population as soon as in 2 to 3 generations.

${ }^{42}$ In line with this, some researchers have claimed that the trait of inhibitory control may be a critical mediator of the domestication syndrome in dogs (Marshall-Pescini et al. 2015). The presence of such inhibitory mechanisms is also supported by the fact that the eye-contact seeking and gaze following behavior of dogs, as well as their bonding to humans, seems to be underpinned by oxytocin release (Romero et al. 2014; Nagasawa et al. 2015).
} 
cultural factors may have jointly contributed to a critical reduction in sympathetic nervous system activity during early childhood, thus enlarging the window of socialization, and enabling distinctly human forms of learning and cooperation to evolve. The present article has highlighted two possible, and interrelated, ways through which this pacification and enculturation process may have proceeded.

\section{Laid-Back: The Infant Default Mode}

One of the points that I have tried to convey throughout this article is that the default mode of infants is that of a motionless and calm alertness, a mode also common to defensively immobilized animals and hypnotized subjects (cf. Peiper 1963; Krojanker 1969; Vrugt and Pederson 1973; Yoshida et al. 2013; Esposito et al. 2015). ${ }^{43}$ This relaxed mode of being, mostly spent in a supine position, plays an important role in their subsequent cognitive development. In particular, it is a prerequisite for the emergence of ToM. It follows from this that disturbances in this default mode can lead to serious developmental problems.

A good case in point is offered, once again, by autism. It has been known for quite some time that autistic children show sensorimotor deficits, for example movement disorders, much earlier than they show cognitive and social deficits (Kanner 1943; P. Teitelbaum et al. 1998; Teitelbaum et al. 2004; Esposito 2011). A particularly interesting expression of this is that autistic children have difficulties in adjusting their bodies to being held and carried, often resulting in comments by their parents such as "I feel as if I am holding a stone" or "It does not feel like a baby, more like a sack of flour" (Esposito et al. 2009, 2015). This rigidity and tension is indicative of a postural dysregulation.

Entering a restful body position and/or a peaceful state of mind is contingent on a successful activation of the parasympathetic nervous system (Benson et al. 1974; Hoffman et al. 1982; Jacobs 2001). This, however, is a difficult task for many autistic people. Several studies have shown that they suffer from a general over-activation of their sympathetic nervous system and a corresponding under-activation of their parasympathetic nervous system (Kushki et al. 2013; Hollocks et al. 2014). This imbalance between sympathetic and parasympathetic tone, between neural excitation and inhibition, could actually help explain some of their developmental problems (Rubenstein and Merzenich 2003).

But how is this imbalance expressed on the neurophysiological level? One possibility is that autistic children suffer from a deficit in cholinergic neurotransmission, as this type

\footnotetext{
$\overline{43}$ This condition is, of course, reminiscent of the transport reflex known from other mammals.
}

of neurotransmission has been shown to play a central role in the regulation of muscle tone. Gall et al. (2007), for example, found that muscle tone in rats, and especially in the neck and spine, is controlled by the interaction between two cholinergic nuclei: the nucleus pontis oralis and the dorsolateral pontine tegmentum. Takakusaki et al. $(2003,2004)$ showed that postural muscle tone and locomotion in cats is controlled by the cholinergic pedunculopontine tegmental nucleus. Similarly, in humans the pedunculopontine nucleus is responsible for gait and postural control (Morita et al. 2014). Importantly, these brainstem nuclei, and adjacent areas, have also been implicated in the control of TI and REM sleep (Lai and Siegel 1990; Klemm 2001; Dergacheva et al. 2002; Hong et al. 2009; Sandoval-Herrera et al. 2011; Liang and Marks 2014).

Several studies have pointed to cholinergic abnormalities in the cerebral cortex and basal forebrain of autistic people. These abnormalities cover the whole gamut and range from pathological involvement of cholinergic nuclei to altered expression of acetylcholine receptors (Perry et al. 2001; Deutsch et al. 2010; Mukaetova-Ladinska et al. 2010). In most cases, these changes amount to a significant reduction in the functionality of the brains cholinergic system. Interestingly, these cholinergic abnormalities also seem to extend to the function of the cerebellum, a recent focus of attention in studies of autism. Lee et al. (2002), for example, found a loss of cholinergic receptors in the cerebellum of autistic persons.

Not surprisingly, correcting these cholinergic deficits is generally beneficial for autism. Karvat \& Kimchi (2014: 831), for example, showed that injections of the acetylcholinesterase inhibitor Donepezil to autistic mice "significantly relieved autism-relevant phenotypes, including decreasing cognitive rigidity, improving social preference, and enhancing social interaction, in a dose dependent manner". Similarly, Langley et al. (2015: 210) found that a "high choline intake during early development can prevent or dramatically reduce deficits in social behavior and anxiety" in an autistic mouse model and that these benefits persisted long after supplementation stopped.

The difficulties of autistic children in entering a restful body position may also be explained by a deficit in oxytocinergic neurotransmission. As described previously oxytocin release is triggered by immobilization, has an anxiolytic effect and inhibits avoidance behaviors during stressful encounters. Studies in both animals and humans have shown that this anxiolytic and inhibitory effect is achieved by a downregulation of the sympathetic nervous system and a simultaneous maintenance of cholinergic vagus nerve activity (Grewen and Light 2011; Kenkel et al. 2013). Hence, a relative lack of this neuropeptide could tip the balance in favor of sympathetic over-activation. In line with this, studies have shown that autistic children suffer from low levels of plasma oxytocin (Modahl et al. 1998; Green et al. 2001) and that correction of this deficit, through oxytocin administration, 
confers considerable symptomatic relief (Green and Hollander 2010; Lee et al. 2015; Auyeung et al. 2015).

\section{Concluding Remarks}

In this article, I have presented a novel hypothesis on the origin of ToM. According to this hypothesis, ToM is evolutionarily descended from two closely related defensive reactions, tonic immobility (TI) and immobilization stress (IS), and in particular from their intentionality detecting component. TI, which is predicated on cholinergic neurotransmission, is triggered by a combination of fearful stimulation, manual restrain, and postural inversion of an animal (i.e., placing it in a supine position) and confers analgesia, leads to flaccid paralysis of the body, maintains visual vigilance and promotes gaze following. Immobilization stress, which is predicated on oxytocinergic neurotransmission, is instead triggered by the forceful immobilization of an animal, and leads to the suppression of avoidance behaviors, confers analgesia, increases attention to the eye region, and facilitates face processing. I believe that the neurophysiology and neuropsychology of these two defensive reactions, closely related as they are, was passed on to humans and became a constitutive part of infantile behavior and a prerequisite of normal cognitive development. In particular, they seem to have facilitated face-to-face interactions, intentional attributions, and inhibitory control. This evolutionary endowment, however, is so well-camouflaged in modern humans that it very easy to miss.

This hypothesis forces us to reconceptualize the standard narrative on parent-child interactions. Parent-child interactions are usually described in highly amicable terms: love, devotion, symbiosis, trust etc. These qualities are, further, believed to lay the foundation for a stable social bond which nourishes the child through its long period of helplessness and also function as a prototype for many later relations and group formations. While this narrative is not necessarily wrong, its overly romanticized view of parent-child interactions may obscure important facts from our consideration, facts that may have an important bearing on the evolutionary origins of ToM. The beginnings of parentchild interactions may, actually, have been far removed from their present state and only reached it through a long series of, mostly counterintuitive, evolutionary, and developmental steps. ${ }^{44}$ In this

\footnotetext{
${ }^{44}$ Physical restraint also seems to be a natural part of childrearing for some monkey species, whose progeny is much more mobile and agile than human babies. This is how Harry Harlow (1963: 6, my italics) describes the interaction between baby and mother during early childhood:

During the first 15 to 25 days of the initial stage of maternal affection, the mother will not allow the infant to leave the living quarters despite the lure which the world outside holds for the infant. Nor is the transition easy for the mothers; they appear torn between restraining their infant and permitting it to leave the home. Gradually, as the mother's efforts to restrain weaken and the infant's efforts to explore increase, the baby escapes, and from this time onward - unless some traumatic events occurs - the baby leaves with increasing frequency and duration.
}

alternative scenario, fear and pain may have played a far more constructive role in the evolution of parent-child interactions than is generally admitted. Mary Ainsworth (1963: 79, 83) and John Bowlby (1983: 203), for example, noted that fear of strangers and a general sense of alarm both trigger and facilitate attachment behavior in children. Similarly, Stephen Porges (2003) has claimed that many prosocial behaviors, including parent-child attachment, are based on a substrate of inherited defense mechanisms (e.g., immobilization).

\section{An Unexpected Relation}

Throughout this text, we have found references to REM sleep, often unexpectedly so. This raises the question as to what kind of relationship REM sleep has to the central tenet of our thesis, namely that ToM evolved from a set of defensive reactions. An answer to this question is offered by a recent study which claims that REM sleep evolved out of the tonic immobility reflex (Tsoukalas 2012). This claim is based on the fact that REM sleep shows striking similarities - on both neurophysiological, phenomenological, and behavioral accounts - to this ancient defense mechanism. Hence, both REM sleep and TI are characterized by EEG desynchronization, cholinergic neurotransmission, brainstem control, generalized inhibition, loss of muscle tone, hippocampal theta waves, eye movements, and thermoregulatory changes. This theory complements the present hypothesis in a crucial way and the interested reader is, therefore, advised to consult it independently. ${ }^{45}$ I will limit myself to a couple of brief comments.

Like its evolutionary ancestor, REM sleep "puts the breaks" on excessive limbic reactivity to threatening stimuli. During REM sleep acetylcholine deactivates part of the prefrontal cortex leaving only the ventromedial prefrontal cortex active to moderate the activity of the amygdala, an intervention that is thought to reprocess previous affective experiences

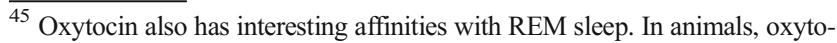
cin administration has been shown to lead to a desynchronization of the EEG (Faure et al. 1959) and has also been implicated in the regulation of the sleepwake cycle (Lancel et al. 2003). Similarly, in humans, oxytocin release leads to drowsiness (Daquin et al. 2001) while exogenous administration increases the amount of REM sleep (Braga et al. 2014). On top of this, oxytocin also has a well-known relationship to melatonin, the human body's main sleeppromoting hormone (Zhdanova et al. 1997). As it happens, the secretion of oxytocin is under the control of melatonin and reaches its peak in the early morning hours when REM sleep begins to dominate over non-REM sleep (Forsling 1993, 2000).

Not surprisingly, melatonin also has a special relationship to defensive reactions. Thus, for instance, it is implicated in the causation of chameleontism (Filadelfi and Castrucci 1996; Hennig et al. 1979; Sugden et al. 2004). Further, it has been found that exposure to aggression and stress increases melatonin production in a number of species (Heinzeller et al. 1988; Lynch and Deng 1986). Similarly, melatonin injections directly potentiate the tonic immobility reaction, a primitive defense reflex (Hennig et al. 1979; Hennig et al. 1980). Finally, melatonin treatment in rats enhances the release of oxytocin in response to immobilization stress (Juszczak 1998).
} 
in a therapeutic direction. ${ }^{46}$ For example, it decreases panic and anxiety reactions and curbs their harmful physiological effects which are driven by aminergic overdrive. (Hartmann 1998; Walker and van der Helm 2009). This effect is not only limited to the sleeping period but, importantly, has been shown to have a residual effect on subsequent wakefulness as well (van der Helm et al. 2011). Given the large amount of REM sleep in infants relative to adults, this residual effect must be massive and could help explain the motionless and calm alertness (and staring spells) so typical of this age. This ranquilizing effect of REM sleep, which protects the organism from excessive sympathetic reactivity accumulated during the day, is unavailable to autistic children due to their intrinsic deficit of REM sleep. ${ }^{47}$

\section{The Evolution of Human Forethought}

Theory of mind is an important part of human forethought. Not surprisingly, it is partly controlled by the prefrontal cortex (Fletcher et al. 1995; Senju and Johnson 2009a; Shepherd 2010) and strongly correlated to measures of executive function (Perner and Lang 1999; Austin et al. 2014). From an evolutionary point of view, however, it might have been the other way around. The emergence and consolidation of ToM may have paved the way for the evolution of the prefrontal cortex, the brains high seat of planning and executive control. ${ }^{48}$ The present hypothesis offers a plausible scenario as to how this may have happened.

There are many ways to conceptualize the prefrontal cortex and its varied functions (Teffer and Semendeferi 2012; Hoffman 2013). A particularly helpful one is to see it as a mainly inhibitory influence on the rest of the brains functions. The suppression of prepotent responses and filtering of distractions is a necessary prerequisite for the generation of sustained attention, a distinguishing

\footnotetext{
$\overline{46}$ The ventromedial prefrontal cortex is also centrally implicated in the expression of social emotions (e.g., guilt, compassion), the suppression of impulsive reactions and in moral decision making (Koenings et al., 2007; Seeley et al., 2016).

47 These findings resonate with Myron Hofer's (1987: 645) claim about the "sleep-embedded nature of nursing." He reported that rat pups separated from their mothers showed a decrease in REM sleep and a corresponding increase in nocturnal arousals and diurnal hyperactivity and concluded that "without interaction with the mother, catecholamine concentrations rise centrally, and the pups become behaviorally hyperresponsive" (ibid. 641).

48 This conjecture, that TI is implicated in the emergence of the prefrontal cortex, is strengthened by an interesting fact. Its "polar opposite" the aminergically driven fight-and-flight reflex seems to have an antagonistic relationship to the prefrontal cortex. Hence, several studies have shown that its many manifestations (e.g., rage, aggression) tend to interfere with or suppress the functions of the prefrontal cortex (van der Kolk et al. 2006; Blair 2012; Koenings 2012).
}

human trait. ${ }^{49}$ Such inhibitory control is especially important during conditions of extensive interference - for example the interference caused by the fight-or-flight reflex (Skinner and Yingling 1977; Shimamura 2000; Fuster 2002; Sullivan and Gratton 2002; Gray and McNaughton 2008; Gold et al. 2015).

Where does this inhibitory power come from? Trying to find an answer, and given all that we have said before, it is difficult not to think of the two reflexes that make up the cornerstones of this thesis, namely TI and IS, which both have well-defined inhibitory properties (e.g., suppression of avoidance behaviors, analgesia, anesthesia). From an evolutionary point of view, they may have provided the inhibitory impetus necessary for the development of the human prefrontal cortex. So how did this evolution look like? Below I offer a rough sketch. For reasons of parsimony, I will focus my attention on the TI reflex. A comparable argument, however, can be made for the evolutionary contribution of the IS reflex. Oxytocin,

${ }^{49}$ This is how Joaquin Fuster (2002: 382-383), a close student of the prefrontal cortex, describes this function:

The neuropsychology of the frontal lobe in humans and monkeys points to another temporal integrative function of the frontal lobe: inhibitory control... The apparent physiological objective of inhibitory influences from orbitomedial cortex is the suppression of internal and external inputs that can interfere with whatever structure or behavior, speech, or cognition is about to be undertaken or currently underway. However, the neurophysiological mechanisms of prefrontal inhibitory control are still unknown.

One source of interference with current structured actions consists of internal biological drives and impulses... Another source of possible interference is a host of influences from sensory systems that are unrelated to current action and can obstruct it or lead it astray... A third source of interference is constituted by motor representations of action that are unrelated to, or in some manner incompatible with, actions currently in the process of temporal structuring. Included among them is a large array of motor habits, tendencies and impulses established in long-term memory and thus in the cortical and subcortical circuitry of motor systems. The suppression of those untoward influences from the motor sector is the essence of the exclusionary aspect of motor attention....

This kind of inhibitory control from the prefrontal cortex is a major component (exclusionary component) of sensory attention. In the absence of it, humans and monkeys with lesions of orbitofrontal cortex exhibit abnormal distractibility in addition to hyperactivity and hyperreactivity to sensory stimuli... The inhibition of distraction complements the intensive, focusing component of selective sensory attention. Both components are supported by prefrontal outputs, which exert control over the cognitive functions of other cortical regions (Desimone \& Duncan, 1995). The attentive control from prefrontal cortex, with its effects of both selective focusing and exclusionary inhibition, is essential for the integrity of any complex structure of goal-directed action....

One of the hallmarks of the psychosocial development of the child is the progressive establishment of inhibitory control over internal impulses, over sensorium, and over motility. As the child grows, the two principal components of attention, inclusive and exclusionary, mature gradually. The child becomes more capable of focusing and concentrating attention on ongoing tasks. At the same time, the child becomes less distractible, less impulsive, and more capable of self-control.

Arthur Shimamura (2000: 211-212), working from the premises of dynamic filtering theory, gives a related account:

the prefrontal cortex operates as a dynamic filtering mechanism that maintains selected neural activations and gates extraneous or irrelevant ones... This mechanism may be particularly involved in inhibiting or damping extraneous activity, or "noise", under conditions of extensive interference... The prefrontal cortex might control neural activity by simply reflecting an inhibitory signal back to the same posterior regions that have recently been active. This form of control amounts to a neural "inhibition of return", which could facilitate attentional shifts. Without this simple control, the system might be subject to perseverations of recent activations. 
too, seems to have had a finger in the game of hominid brain evolution (Carter 2014).

In reptiles, amphibians and birds $\mathrm{TI}$ is a ubiquitous and well-formed reflex. But with the transition to mammals, it almost disappears. How can we explain such a swift, phylogenetically speaking, disappearance? What happened to it? The answer favored here is that the reorganization of the mammalian brain gradually absorbed this primitive reflex and made it an integral part of its structure and function. ${ }^{50}$ As new neural structures emerged around the TI module, its various components (inhibition, visual vigilance etc.) started to uncouple from each other and became embedded in different limbic and cortical circuits: one part leading to the postural atonia of REM sleep (Tsoukalas 2012), another leading to the transport reflex (Prestrude 1977; Webster et al. 1981; Meyer et al. 1984), and yet another becoming a contributor in the formation of the behavioral inhibition system or BIS (Gray 1982: 480-481). ${ }^{51}$ In humans, this process went even further and eventually gave rise to such higher order capabilities as sustained attention and suggestibility (Cortez and Silva 2013), guilt and shame (Bovin et al., 2014), reflective thinking (Patterson \& Newman, 1993; Erhard et al., 1999), parentchild attachment (Porges 2003) and the intentionality detector of ToM (Baron-Cohen 1995). As a result of this evolutionary process, TI lost its distinctive character and "disappeared from the map." Today, its existence is only attested by the inhibitory function, visual vigilance, and altered states of consciousness of some of its derivatives.

But what, more precisely, prompted the unique configuration of the human prefrontal cortex? After all, many mammals have a prefrontal cortex but very few of them exhibit humanlike behaviors. The answer is extreme neoteny. As several authors have shown, such infantilization was advantageous and eventually lead, through compensatory changes in brain architecture, to the emergence of distinctly human traits and human culture. The most important of these "compensatory changes" was the enlargement and/or reorganization of the

\footnotetext{
$\overline{{ }^{50}}$ This transformation was part of a wider evolutionary process that eventually led to the evolution of the limbic system and the neocortex (Eccles 1989; MacLean 1990).

${ }^{51}$ Gray and McNaughton (2008) consider various ancestral defense mechanisms to have laid the foundation of the BIS. However, they focus on the freeze response and passive avoidance and do not mention the TI reflex. This is unfortunate for several reasons. Firstly, TI is related to the aforementioned reactions in the context of the defensive cascade and should, therefore, also have contributed to the phylogenetic origin of the BIS. Secondly, it represents a much more dramatic reaction; compared to it both the freeze response and passive avoidance are just minor instances of behavioral inhibition. Thirdly, and perhaps most importantly, TI is inherently related to the generation of theta rhythms, a central feature of the septo-hippocampal complex. Actually, these rhythms are one of the defining features of TI (Rakshit and Klemm 1980; Fontani et al. 1982). According to Gray and McNaughton (2008) theta rhythms are responsible for producing the anxiety typical of the BIS system, and are effectively silenced by many anxiolytic drugs. Other researchers, however, have connected theta rhythms to pleasurable feelings, drowsiness, creativity, and meditative states (Schacter 1977; Gruzeler 1998; Jensen et al. 2015).
}

human prefrontal cortex (Holloway 1981; Somel et al. 2009; Thompson-Schill et al. 2009). The effect of neoteny was probably three-partite.

Firstly, the progressive infantilization of the species placed humans under the prolonged influence of various mammalian reflexes related to immobilization, reflexes which in other animals are only operative for a short time after birth. Two examples of such reflexes are TI and IS. Both these reflexes are prevalent during infancy, suppress aggressive behaviors and avoidance maneuvers during stressful encounters, and include an intentionality detector which works through the monitoring of eye movements (Prestrude 1977; Hennig 1977; McCarthy et al. 1991; Porter et al. 1998; Guastella et al. 2008; Domes et al. 2013; Danevova et al. 2013; Rousseau et al. 2014).

Secondly, neoteny also resulted in a temperamental shift leading to a more contemplative and cooperative mood so typical of human beings. This shift has also been observed in a number of domesticated animals and has been linked to the production of human-like cognitive abilities like theory of mind and advanced forms of communication (Hare \& Tomasello, 2009; Hare et al. 2012). Closer studies in domesticated animals have revealed that this temperamental shift is predicated on a weakening of the hypothalamic-pituitaryadrenal system and a reduction of aggressive behaviors (Belyaev 1984; Osadschuk 1997; Künzl and Sachser 1999; Trut et al. 2004; Albert et al. 2008; Trut et al. 2009). This reduction in sympathetic drive led to a corresponding enlargement of the "socialization window," a necessary condition for the acculturation of new generations.

Thirdly, neoteny enabled humans to lie down in the supine position, a position which is anatomically difficult to achieve for many other mammals (Morris 1967; Michel and Goodwin 1979). When other mammals do exhibit it, it is usually as a sign of defeat and submission (Grant 1963; Grant and Mackintosh 1963; Dixon 1998). The supine position afforded human infants the opportunity to engage in face-to-face interactions with their parents, a fact that enabled them to develop cognitive and prosocial abilities out of reach for other mammalian species (Takeshita et al. 2009).

Is there any empirical support for this, admittedly speculative, claim? As always, finding direct evidence for evolutionary claims is a difficult task. There is, however, plenty of indirect evidence. A piece of evidence comes from studies of the functional specialization of the prefrontal cortex. As it turns out, with few exceptions, "it is not possible to ascribe a specific physiological function to any prefrontal area" (Fuster 2002: 373). The exception alluded to above is provided by the frontal eye fields, an area devoted specifically to the control of gaze following and REM, and usually identified with Broadmann's area $8{ }^{52}$ How can we interpret this surprising

52 In some studies, using different brain mapping nomenclatures, the frontal eye fields have also been identified with areas 6 and/or 45 (Vernet et al. 2014). 
finding? The interpretation favored here is that this is a remnant of the evolutionary history of the prefrontal cortex, which has its beginnings in the inhibitory control and visual vigilance inherent in defensive immobilization.

This conjecture is also supported by the psychological functions encoded by Broadmann's area 8. Magnetic resonance studies have shown that this area is implicated in the management of uncertainty, becoming intensely activated whenever subjects experience uncertainty (Volz et al. 2005). This activation of the prefrontal cortex could also encode hope, a higher order expectation positively correlated to uncertainty (Chew and Ho 1994). In any case, both these emotions could easily be ascribed to the residual influence of TI or IS; for an animal captured by a predator uncertainty could not be higher and hope more vital.

If we look at the dorsolateral prefrontal cortex, the phylogenetically and ontogenetically most recent addition to the human brain, the plot thickens even more. In this brain region, which includes area 8 , we find one of the control mechanisms of ToM (see Introduction). Furthermore, studies have shown that this brain region is activated by threat-induced vigilance. The same study showed that people who are more inhibited than others have a higher tonic activity in the right-posterior dorsolateral prefrontal cortex. Not surprisingly, dysfunction of this area has been shown to correlate with difficulties in complex problem solving (Shackman et al. 2009). Interestingly, recent studies have uncovered the possibility of cholinergic neurotransmission in this area (Yang et al. 2013), an important finding as this area was previously thought to be predominantly under the influence of dopaminergic neurotransmission.

Finally, several studies have shown that ToM predates the development of other prefrontal faculties. For example, both Hughes and Ensor (2007) and Austin et al. (2014) found partial support for early ToM predicting the development of later executive functions (though evidence of the reverse relationship was also found). More decisively, Morales et al. (2005) found that the attentional and gaze-following skills of children at 6 months of age predicted their ability to regulate emotions at 24 months while MacAlister and Peterson (2013) found that ToM during the preschool years predicted the development of executive functions 1 year later (but not vice versa). Although these studies are preliminary, and the interpretation of their findings is difficult, the available results make good sense from the point of view of our hypothesis.

\section{An Ontogenetic Sketch}

The study by Rousseau et al. (2014) showed, for the first time, that $\mathrm{TI}$ is a part of normal neonatal development. ${ }^{53}$ But what is the developmental fate of this ancestral reflex? Pending

\footnotetext{
${ }^{53}$ Its influence on childhood psychopathology, however, has been known for quite some time (Chu et al. 1999; Heidt et al. 2005; Humphreys et al. 2010).
}

further investigation we can make some well-grounded speculations. Many other primitive reflexes are present around or shortly after birth (e.g., the palmar grasp reflex, the parachute reflex, the Moro reflex). As the brain develops, over the first years of life connections to higher centers are strengthened and increasingly take over the functions of these primitive reflexes. In this way, early survival patterns are gradually tempered and superseded by more mature patterns of response (Zafeiriou 2004; Goddard 2005). ${ }^{54}$

This probably also happens with neonatal TI. During development the subcortical circuit of ToM, which is faster and informationally encapsulated, becomes coupled to a cortical circuit, which is slower and more context and task sensitive, and this maturation process eventually leads to the prefrontal cortex assuming considerable control of this mental faculty (Fletcher et al. 1995; Senju and Johnson 2009a; Shepherd 2010). A proof of this comes from the fact that, in the relatively few mammals that show full-fledged TI, the neocortex seems to antagonize its initiation in mature individuals (Teschke et al. 1975; Klemm 2001).

In addition to this neuroanatomical integration, there is probably also a change in the character of the mental representations involved. According to Annette Karmiloff-Smith (1994), an important aspect of childhood development is the gradual translation of knowledge into increasingly higher level formats: from implicit to explicit and from procedural to declarative. Such representational redescription "increases the flexility and manipulability of the knowledge stored in the mind, by turning information that is in the mind into progressively more explicit knowledge to the mind" (ibid. 698). This process, however, does not obliterate the original formats but instead results in the existence of multiple representations of the same or similar knowledge in different formats. The increasing sophistication of the ToM faculty with age, and its cortical preponderance, bespeaks such a redescription process.

\section{Out of the Closet}

Thanks to the seminal works of Walter Canon (1915) and Hans Selye $(1936,1955)$, every psychology student knows about the importance of the fight-or-flight reflex.

\footnotetext{
${ }^{54}$ A graphic illustration of such a developmental process is offered by the phenomenon of night terrors. This peculiar sleep disturbance, common in preschool children, is the result of partial awakenings from deep, non-REM, sleep. These partial awakenings leave the child in state of dissociation and are accompanied by screams, struggling, and locomotion. After each episode, the child usually goes back to sleep with hardly any memory of the event. According to several sleep researchers these dramatic behaviors are runaway instances of the fight-or-flight reflex (Ferber 2006; Schenck 2008). It is this reflex that explains the screaming and struggling of sleep terrors - the child tries to fight or flee from something. With growing age these disturbances, which are completely normal in childhood, gradually wane and eventually disappear altogether.
} 
Unfortunately, a comparable development never occurred with regards to tonic immobility. Even today, very few people now about TI, and even fewer know of its relevance for human health and well-being. ${ }^{55}$ Part of the explanation is the fact that this reflex is well-camouflaged among higher primates, in contrast to its more assertive "cousin" which is in plain sight. In the pages of this article, I have tried to open up a window into its fascinating world by showing how it might have contributed to the evolution ToM. Other scholars have also emphasized the importance of this behavioral disposition and, in closing this article, I would like to briefly highlight some of their thoughts.

According to Stephen Porges (2003), defensive immobilization was through successive stages of mammalian evolution, co-opted by the cortex to support various forms of social engagement including those of parent-child interactions. Mammals have a natural tendency to be on-guard when they meet other individuals - whether of their own or different species - and can easily be pushed into defensive maneuvers and even fight-or-flight. This tendency, however, needs to be curbed in order for certain necessary prosocial behaviors to occur. In humans, these defensive reactions can be inhibited if a cognitive appraisal signals that the environment is safe. In such a case, the brain releases of endogenous opiates and oxytocin which pacify the limbic system and produce analgesia and euphoria. ${ }^{56}$ The end result of this process is immobilization without fear, a kind of tactical surrender. This quiescence - a condition reminiscent of the hypnotic trance - is a prerequisite for successful parent-child attachment, nursing behaviors and pair bond formation (cf. Peiper 1963; Krojanker 1969; Vrugt and Pederson 1973).

Brian Hare (2007) has claimed that the evolutionary selection of animals with less reactive temperaments supported the development of sophisticated social-cognitive skills in several

\footnotetext{
$\overline{55}$ The only field where the importance of tonic immobility for human life has been fully recognized is that of trauma studies (Suarez and Gallup 1976; Gallup and Rager 1996; Dixon 1998; Abrams et al. 2009; Levine 2010). In this field, a number of neurophysiologists and psychotherapists have theorized that TI may be a central element of many peritraumatic reactions (e.g., dissociation, paralysis, amnesia, muteness). Despite their different focus (focusing on the pathological as opposed to the physiological), these studies have been a great influence on my thinking around TI.

These studies also underscore an important point which I have consciously avoided to comment on until now. Tonic immobility is not an innocuous reaction. When it has been observed in humans, it has mostly been under pathological circumstances, for example in the paralysis and dissociation of rape victims. This does not mean, however, that the reaction itself is pathologic. This is an important distinction which is increasingly being accepted (Porges 2003; Rousseau et al. 2014). There is, in this regard, an interesting parallelism to the fight-and-flight reflex which also seems to figure prominently in various psychopathological states, from panic attacks to night terrors. The function of these two reflexes, hence, seems to be "Janus-faced": when regulated and unperturbed they perform vital functions for the organism, when deregulated and perturbed they wreak havoc on the organism.

${ }^{56}$ For more details on how this is achieved see McCarthy et al. (1991), Nelson and Panksepp (1998), Kosfeld et al. (2005), Zak et al. 2007 and Theodoridou et al. (2009).
}

species, including humans. Evolution may thus have favored the enlargement of areas related to passive avoidance and appeasement, like the septal area and prefrontal cortex, while simultaneously attenuating the function of areas related to rage and aggression, like the amygdala (cf. Eccles 1989: $105-106,113){ }^{57}$ Tonic immobility may have played a role in this scenario. As mentioned previously, TI is antithetical to the fight-and-flight reflex and as such abolishes panic reactions and aggressive behavior. This feat is achieved through a direct inhibition of the amygdala (Leite-Panissi et al. 2003; da Silva and Menescal-de-Oliveira 2006; Favaroni Mendes and Menescal-de-Oliveira 2008). Hence, the continued presence of TI in human life, even in transmuted form, may have contributed to this "domestication" of the human species.

Finally, we ought to mention Herbert Benson and his work on the relaxation response (Benson et al. 1974). This work showed that the human body harbors an innate mechanism that opposes the ravages of the fight-or-flight reflex and promotes relaxation, as well as a number of other parasympathetic "virtues" (e.g., rest, recuperation, immunity). This response shows an intriguing overlap with some of the workings of oxytocin (Uvnäs-Moberg 1997). Although Benson never traced the phylogenetic origins of this response to defensive immobilization he increased both public and scholarly awareness of its importance and practical utilization.

Open Access This article is distributed under the terms of the Creative Commons Attribution 4.0 International License (http:// creativecommons.org/licenses/by/4.0/), which permits unrestricted use, distribution, and reproduction in any medium, provided you give appropriate credit to the original author(s) and the source, provide a link to the Creative Commons license, and indicate if changes were made.

\section{References}

Abelson, K. S., Kommalage, M., \& Höglund, A. U. (2004). Spinal cholinergic involvement after treatment with aspirin and paracetamol in rats. Neuroscience Letters, 368, 116-120.

Abrams, M. P., Carleton, R. N., Taylor, S., \& Asmundson, G. J. (2009). Human tonic immobility: measurement and correlates. Depression and Anxiety, 26, 550-556.

\footnotetext{
${ }^{57}$ The precise function of the septal area is still elusive and, hence, conflicting results do exist. It is becoming increasingly clear, however, that it plays an important role in response inhibition and fear conditioning. Several studies have shown that septal lesions abolish, or greatly diminish, freezing reactions and passive avoidance and instead promote rewarded responding, active avoidance and resistance to extinction (McCleary 1966; Slotnick and Jarvik 1966; Blatt 1976; Gray and McNaughton 1983; Mongeau et al. 2003). It is also interesting to note that the septal area has one of the highest densities of oxytocin in the mammalian brain (Lieberman 2013: 160).

An interesting finding is that lesions of the septal area potentiate the TI reflex (Woodruff 1977). A possible interpretation of these results is that the septal area and the brainstem areas controlling TI together constitute a 'dual inhibitory filter' (in humans there is a third filter in the form of the prefrontal cortex). When the first filter (septal) is breached the animal becomes severely disinhibited and anxious thus easily coming under the influence of the second filter (TI).
} 
Ainsworth, M. D. (1963). The development of infant-mother interaction among the Ganda. In B. M. Foss (Ed.), Determinants of infant behaviour (Vol. 2, pp. 67-104). London: Methuen and Co..

Albert, F. W., Shchepina, O., Winter, C., Römpler, H., Teupser, D., Palme, R., Ceglarek, U., Kratzsch, J., Sohr, R., Trut, L. N., Thiery, J., Morgenstern, R., Plyusnina, I. Z., Schöneberg, T., \& Pääbo, S. (2008). Phenotypic differences in behavior, physiology and neurochemistry between rats selected for tameness and for defensive aggression towards humans. Hormones and Behavior, 53(3), 413-421.

Alboni, P., Alboni, M., \& Bertorelle, G. (2008). The origin of vasovagal syncope: to protect the heart or to escape predation? Clinical Autonomic Research, 18(4), 170-178.

Alboni, P., \& Alboni, M. (2014). Vasovagal syncope as a manifestation of an evolutionary selected trait. Journal of Atrial Fibrillation, 7(2), 1035.

Ardiel, E. L., \& Rankin, C. H. (2010). The importance of touch in development. Pediatrics and Child Health, 15(3), 153-156.

Arsikan, B., Paez-Gonzalez, P., Erb, J., \& Kuo, C. T. (2016). Cholinergic circuit control of postnatal neurogenesis. Neurogenesis, 3(1), e1127310.

Aserinsky, E., \& Kleitman, N. (1953). Regularly occurring periods of eye motility, and concomitant phenomena, during sleep. Science, $118(3062), 273-274$.

Austin, G., Groppe, K., \& Elsner, B. (2014). The reciprocal relationship between executive function and theory of mind in middle childhood: a 1-year longitudinal perspective. Frontiers in Psychology, 5, 655.

Auyeung, B., Lombardo, M. V., Heinrichs, M., Chakrabarti, B., Sule, A., Deakin, J. B., Bethlehem, R. A. I., Dickens, L., Mooney, N., Sipple, J. A. N., Thiemann, P., \& Baron-Cohen, S. (2015). Oxytocin increases eye contact during a real-time, naturalistic social interaction in males with and without autism. Translational Psychiatry, 5, e507.

Bae, Y. J., Kim, J. H., Choi, B. S., Jung, C., \& Kim, E. (2013). Brainstem pathways for horizontal eye movement: pathologic correlation with MR imaging. Radiographics, 33(1), 47-59.

Baron-Cohen, S. (1995). The eye direction detector (EDD) and the shared attention mechanism (SAM): two cases for evolutionary psychology. In C. Moore \& P. J. Dunham (Eds.), Joint attention. Its origins and role in development (pp. 41-59). New York: Psychology Press.

Baron-Cohen, S., Wheelwright, S., \& Jolliffe, T. (1997). Is there a "language of the eyes"? Evidence from normal adults, and adults with autism or Asperger syndrome. Visual Cognition, 4(3), 311-331.

Barrett, D. L. (1979). The hypnotic dream: its relation to nocturnal dreams and waking fantasies. Journal of Abnormal Psychology, 88(5), 584 591.

Barrowcliff, A. L., Gray, N. S., Freeman, T. C. A., \& MacCulloch, M. J. (2004). Eye-movements reduce the vividness, emotional valence and electrodermal arousal associated with negative autobiographical memories. Journal of Forensic Psychiatry and Psychology, 15(2), $325-345$.

Bauer, P. (2007). Recall in infancy: a neurodevelopmental account. Current Directions in Psychological Science, 16(3), 142-146.

Belyaev, D. K. (1984). Foxes. In I. L. Mason (Ed.), Evolution of domesticated animals (pp. 211-214). New York: Longman.

Benson, H., Beary, J. F., \& Carol, M. P. (1974). The relaxation response. Psychiatry, 37(1), 37-46.

Biever, J. A., \& Karinch, M. (2012). The wandering mind: understanding dissociation from daydreams to disorders. Rowman \& Littlefield Publishers.

Bjorklund, D. F. (1987). A note on neonatal imitation. Developmental Review, 7, 86-92.

Blair, R. J. R. (2012). Considering anger from a cognitive neuroscience perspective. Wiley Interdisciplinary Review of Cognitive Science, $3(1), 65-74$.
Blanc, J. J., \& Benditt, D. G. (2016). Vasovagal syncope: hypothesis focusing on its being a clinical feature unique to humans. Journal of Cardiovascular Electrophysiology, 27(5), 623-629.

Blatt, R. C. (1976). Facilitation and nonfacilitation of active avoidance behavior of rats with septal lesions in the shuttlebox and running wheel. Journal of Comparative Physiological Psychology, 90(7), 704-713.

Blumberg, M. S. (2013). Ontogeny of sleep. In C. Kushida (Ed.), The encyclopedia of sleep (Vol. Volume 1, pp. 32-37). Waltham, MA: Academic Press.

Blumberg, M. S., Karlsson, K. A., Seelke, A. M. H., \& Mohns, E. J. (2005). The ontogeny of mammalian sleep: a response to Frank and Heller (2003). Journal of Sleep Research, 14(1), 91-98.

Borrow, A. P., \& Cameron, N. M. (2012). The role of oxytocin in mating and pregnancy. Hormones and Behavior, 61(3), 266-276.

Botly, L. C., \& de Rosa, E. (2008). A cross-species investigation of acetylcholine, attention, and feature binding. Psychological Science, 19(11), 1185-1193.

Boucetta, S., Cissé, Y., Mainville, L., Morales, M., \& Jones, B. E. (2014). Discharge profiles across the sleep-waking cycle of identified cholinergic, GABAergic, and glutamatergic neurons in the pontomesencephalic tegmentum of the rat. The Journal of Neuroscience, 34(13), 4708-4727.

Bovin, M. J., Dodson, T. S., Smith, B. N., Gregor, K., Marx, B. P., \& Pineles, S. L. (2014). Does guilt mediate the association between tonic immobility and posttraumatic stress disorder symptoms in female trauma survivors? Journal of Traumatic Stress, 27 (6): 721-724.

Bowlby, J. (1983). Attachment (2nd ed.). Basic Books.

Brady, J. P., \& Rosner, B. S. (1966). Rapid eye movements in hypnotically induced dreams. The Journal of Nervous and Mental Disease, 143(1), 28-35.

Braga, R. I., Panaitescu, A., Bădescu, S., Zăgrean, A. M., \& Zăgrean, L. (2014). Intranasal administration of oxytocin alters sleep architecture. Biological Rhythm Research, 45(1), 69-75.

Brewster, J., \& Leon, M. (1980). Facilitation of maternal transport by Norway rat pups. Journal of Comparative and Physiological Psychology, 94(1), 80-88.

Brothers, L., Ring, B., \& Kling, A. (1990). Response of neurons in the macaque amygdala to complex social stimuli. Behavioural and Brain Research, 41(3), 199-213.

Brothers, L., \& Ring, B. (1993). Mesial temporal neurons in the macaque monkey with responses selective for aspects of social stimuli. Behavioural and Brain Research, 57(1), 53-61.

Buckley, A. W., Rodriguez, A. J., Jennison, K., Buckley, J., Thurn, A., Sato, S., \& Swedo, S. (2010). REM sleep percentage in children with autism compared to children with developmental delay and typical development. Archives of Pediatrics and Adolescent Medicine, 164(11), 1032-1037.

Callaway, C. W., Lydic, R., Baghdoyan, H. A., \& Hobson, J. A. (1987) Pontogeniculooccipital waves: spontaneous visual system activity during rapid eye movement sleep. Cellular and Molecular Neurobiology, 7(2), 105-149.

Camras, L. A., Oster, H., Campos, J. J., Miyake, K., \& Bradshaw, D. (2005). Japanese and American infants' responses to arm restraint (pp. 289-299). In P. Ekman \& E. L. Rosenberg (Eds.), What the face reveals. Oxford, UK: Oxford University Press.

Canon, W. B. (1915). Bodily changes in pain, hunger, fear and rage: an account of recent researches into the function of emotional excitement. New York: Appleton-Century-Crofts.

Cantero, J. L., Atienza, M., Stickgold, R., Kahana, M. J., Madsen, J. R., \& Kocsis, B. (2003). Sleep-dependent theta oscillations in the human hippocampus and neocortex. The Journal of Neuroscience, 23(34), 10897-10903.

Caputo, G. B. (2015). Dissociation and hallucinations in dyads engaged through interpersonal gazing. Psychiatry Research, 228(3), 659663. 
Carli, G. (1977). Animal hypnosis in the rabbit. The Psychological Record, 27, 123-143.

Carlson, S. M., \& Moses, L. J. (2001). Individual differences in inhibitory control and children's theory of mind. Childhood Development, 72(4), 1032-1053.

Carmant, L., Kramer, U., Holmes, G. L., Mikati, M. A., Riviello, J. J., \& Helmers, S. L. (1996). Differential diagnosis of staring spells in children: a video-EEG study. Pediatric Neurology, 14(3), 199-202.

Carter, C. S. (2014). Oxytocin pathways and the evolution of human behavior. Annual Reviews of Psychology, 65, 17-39.

Chance, M. R. A. (1967). Attention structure as the basis of primate rank orders. Man, 2(4), 503-518.

Chasiotis, A., Kiessling, F., Hofer, J., \& Campos, D. (2006). Theory of mind and inhibitory control in three cultures: conflict inhibition predicts false belief understanding in Germany, Cost Rica and Cameroon. International Journal of Behavioral Development, 30(3), 249-260.

Chew, S. H., \& Ho, J. L. (1994). Hope: an empirical study of attitude toward the timing of uncertainty resolution. Journal of Risk and Uncertainty, 8(3), 267-288.

Chu, J. A., Frey, L. M., Ganzel, B. L., \& Matthews, J. A. (1999). Memories of childhood abuse: dissociation, amnesia, and corroboration. The American Journal of Psychiatry, 156(5), 749-755.

Cohen, H. B., \& Dement, W. C. (1970). Prolonged tonic convulsions in REM deprived mice. Brain Research, 22(3), 421-422.

Connolly, A. C., Sha, L., Guntupalli, J. S., Oosterhof, N., Halchenko, Y. O., Nastase, S. A., di Oleggio Castello, M. V., Abdi, H., Jobst, B. C., Gobbini, M. I., \& Haxby, J. V. (2016). How the human brain represents perceived dangerousness or "predacity" of animals. The Journal of Neuroscience, 36(19), 5373-5384.

Corbetta, M., Patel, G., \& Shulman, G. L. (2008). The reorienting system of the human brain: from environment to theory of mind. Neuron, $58(3), 306-324$.

Cortez, C. M., \& Silva, D. (2013). Hypnosis, tonic immobility and electroencephalogram. Jornal Brasileiro de Psiquiatria, 62(4), 285-296 article in Portuguese.

Crawford, H. J. (1994). Brain dynamics and hypnosis: attentional and disattentional processes. International Journal of Clinical and Experimental Hypnosis, 52(3), 204-232.

Crawford, H. J. (2001). Neuropsychophysiology of hypnosis: towards an understanding of how hypnotic interventions work. In G. D. Burrows, R. O. Stanley, \& P. B. Bloom (Eds.), International handbook of clinical hypnosis (pp. 61-82). New York: John Wiley \& Sons.

Dalton, K. M., Nacewicz, B. M., Johnstone, T., Schaefer, H. S., Gernsbacher, M. A., Goldsmith, H. H., Alexander, A. L., \& Davidson, R. J. (2005). Gaze fixation and the neural circuitry of face processing in autism. Nature Neuroscience, 8 (4): 519-526.

Danevova, V., Kvetnansky, R., \& Jezova, D. (2013). Kinetics of oxytocin response to repeated restraint stress and/or chronic cold exposure. Hormone and Metabolic Research, 45(12), 845-848.

Daquin, G., Micallef, J., \& Blin, O. (2001). Yawning. Sleep Medicine Reviews, 5(4), 299-312.

da Silva, L. F., \& Menescal-de-Oliveira, L. (2006). Cholinergic modulation of tonic immobility and nociception in the NRM of guinea pig. Physiology and Behavior, 87(4), 821-827.

Datta, S., \& Maclean, R. R. (2007). Neurobiological mechanisms for the regulation of mammalian sleep-wake behavior: reinterpretation of historical evidence and inclusion of contemporary cellular and molecular evidence. Neuroscience \& Biobehavioral Reviews, 31(5), $775-824$.

Davie, P. S., Franklin, C. E., \& Grigg, G. C. (1993). Blood pressure and heart rate during tonic immobility in the black tipped reef shark, Carcharinus melanoptera. Fish Physiology and Biochemistry, 12(2), 95-100.
Dergacheva, O., Khachikova, I. E., \& Burikov, A. A. (2002). Impulse activity of neurons in the nucleus pontis oralis in cats during sleepwakefulness cycle. Russian Journal of Physiology (Ross Fiziol Zh Im I M Sechenova), 88(12), 1530-1537.

Descarries, L., Mechawar, N., Aznavour, N., \& Watkins, K. (2004). Structural determinants of the roles of acetylcholine in cerebral cortex. Progress in Brain Research, 145, 45-58.

Desimone, R., \& Duncan, J. (1995). Neural mechanisms of selective visual attention. Annual Review of Neuroscience, 18: 193-222.

Deutsch, S. I., Urbano, M. R., Neumann, S. A., Burket, J. A., \& Katz, E. (2010). Cholinergic abnormalities in autism: is there a rationale for selective nicotinic agonist interventions? Clinical Neuropharmacology, 33(3), 114-120.

Devnani, P. A., \& Hedge, A. U. (2015). Autism and sleep disorders. Journal of Pediatric Neurosciences, 10(4), 304-307.

de Waal, F. B. M. (1989). Peacemaking among primates. Cambridge, MA: Harvard University Press.

Dixon, A. K. (1998). Ethological strategies for defence in animals and humans: their role in some psychiatric disorders. British Journal of Medical Psychology, 71(Pt 4), 417-445.

Domes, G., Steiner, A., Porges, S. W., \& Heinrichs, M. (2013). Oxytocin differentially modulates eye gaze to naturalistic social signals of happiness and anger. Psychoneuroendocrinology, 38(7), 11981202.

Doricchi, F., Guariglia, C., Paolucci, S., \& Pizzamiglio, L. (1993). Disturbances of the rapid eye movements (REMs) of REM sleep in patients with unilateral attentional neglect: clue for the understanding of the functional meaning of REMs. Electroencephalography and Clinical Neurophysiology, 87(3), $105-116$.

Dussor, G. O., Helesic, G., Hargreaves, K. M., \& Flores, C. M. (2004). Cholinergic modulation of nociceptive responses in vivo and neuropeptide release in vitro at the level of the primary sensory neuron. Pain, 107(1-2), 22-32.

Eccles, J. C. (1989). Evolution of the brain: creation of the self. London: Routledge.

Eisenach, J. C., Detweiler, D. J., Tong, C., D'Angelo, R., \& Hood, D. D. (1996). Cerebrospinal fluid norepinephrine and acetylcholine concentrations during acute pain. Anesthesia and Analgesia, 82(3), 621-626.

Ekman, P. (2003). Emotions revealed. Recognizing faces and feelings to improve communication and emotional life. New York: St. Martin's Griffin.

Elkins, G., Jensen, M. P., \& Patterson, D. R. (2007). Hypnotherapy for the management of chronic pain. The International Journal of Clinical and Experimental Hypnosis, 55(3), 275-287.

Emde, R. N., \& Koenig, K. L. (1969). Neonatal smiling and rapid eye movement states. Journal of the American Academy of Child Psychiatry, 8(1), 57-67.

Emery, N. J. (2000). The eyes have it: the neuroethology, function and evolution of social gaze. Neuroscience and Biobehavioral Reviews, 24(6), 581-604.

Erhard, H. W., Mendl, M., \& Christiansen, S. B. (1999). Individual differences in tonic immobility may reflect behavioural strategies. Applied Animal Behaviour Science, 64 (1): 31-46.

Esposito, G., Venuti, P., Maestro, S., \& Muratori, F. (2009). An exploration of symmetry in early autism spectrum disorders: analysis of lying. Brain Development, 31(2), 131-138.

Esposito, G. (2011). Early postures and gait development in Autism Spectrum Disorders (ASD). Neuroscience Research, 71(1), 101102.

Esposito, G., Setoh, P., Yoshida, S., \& Kuroda, K. O. (2015). The calming effect of maternal carrying in different mammalian species. Frontiers in Psychology, 6(445), 1-6. 
Farroni, T., Csibra, G., Simion, F., \& Johnson, M. H. (2004a). Eye contact detection in humans from birth. Proceedings of the National Academy of Sciences of the U.S.A., 99(14), 9602-9605.

Farroni, T., Johnson, M. H., \& Csibra, G. (2004b). Mechanisms of eye gaze perception during infancy. Journal of Cognitive Neuroscience, 16(8), 1320-1326.

Faure, J., Loiseau, P., \& Friconneau, C. (1959). Influence of oxytocin on the electroencephalogram in the rabbit. Revista de Obstetricia y Ginecologia de Venezuela, 101, 302-308.

Favaroni Mendes, L. A., \& Menescal-de-Oliveira, L. (2008). Role of cholinergic, opioidergic and GABAergic neurotransmission of the dorsal hippocampus in the modulation of nociception in guinea pigs. Life Sciences, 83(19-20), 644-650.

Feldman, R., Weller, A., Zagoory-Sharon, O., \& Levine, A. (2007). Evidence for a neuroendocrinological foundation of human affiliation: plasma oxytocin levels across pregnancy and the postpartum period predict mother-infant bonding. Psychological Science, 18(11), 965-970.

Ferber, R. (2006). Solve your child's sleep problems. New York, NY: Fireside Books.

Field, T., \& Diego, M. (2008). Vagal activity, early growth and emotional development. Infant Behavior \& Development, 31(3), 361-373.

Filadelfi, A. M., \& Castrucci, A. M. (1996). Comparative aspects of the pineal/melatonin system of poikilothermic vertebrates. Journal of Pineal Research, 20(4), 175-186.

Fletcher, P. C., Happè, F., Frith, U., Baker, S. C., Dolan, R. J., Frackowiak, R. S., \& Frith, C. D. (1995). Other minds in the brain: a functional imaging study of "theory of mind" in story comprehension. Cognition, 57(2), 109-128.

Fonagy, P., \& Target, M. (1997). Attachment and reflective function: their role in self-organization. Development and Psychopathology, 9(4), 679-700.

Fontani, G., Grazzi, F., Lombardi, G., \& Carli, G. (1982). Hippocampal rhythmic slow activity (RSA) during animal hypnosis in the rabbit. Behavioural Brain Research, 6(1), 15-24.

Forrest, D. (1999). Hypnotism. A history. London: Penguin Books.

Forsling, M. (1993). Neurohypophysial hormones and circadian rhythm. In W. North, A. Moses, \& L. Share (Eds.), The neurohypophysis: a window on brain function (pp. 382-395). New York, NY: New York Academy of Sciences.

Forsling, M. (2000). Diurnal rhythms in neurohypophysial function. Experimental Physiology, 85(1), 179-186.

Franco, P., Seret, N., van Hess, J. N., Scaillet, S., Groswasser, J., \& Kahn, A. (2005). Influence of swaddling on sleep and arousal characteristics of healthy infants. Pediatrics, 115(5), 1307-1311.

Frank, M. G., \& Heller, C. (2003). The ontogeny of mammalian sleep: a reappraisal of alternative hypotheses. Journal of Sleep Research, 12, 25-34.

Franklin, M. S., \& Zyphur, M. J. (2005). The role of dreams in the evolution of the human mind. Evolutionary Psychology, 3, 59-78.

Frenken, R. (2011). Psychology and history of swaddling. Part one: antiquity until 15th century. The Journal of Psychohistory, 39(2), 84 114

Frenken, R. (2012). Psychology and history of swaddling. Part two: the abolishment of swaddling from the 16th century until today. The Journal of Psychohistory, 39(3), 219-245.

Fuster, J. M. (2002). Frontal lobe and cognitive development. Journal of Neurocytology, 31(3-5), 373-385.

Gabel, S. (1988). The right hemisphere in imagery, hypnosis, rapid eye movement sleep and dreaming. Empirical studies and tentative conclusions. The Journal of Nervous and Mental Disease, 176(6), 323331.

Gall, A. J., Poremba, A., \& Blumberg, M. S. (2007). Brainstem cholinergic modulation of muscle tone in infant rats. The European Journal of Neuroscience, 25(11), 3367-3375.
Gallup, G. G. (1977). Tonic immobility: the role of fear and predation. The Psychological Record, 27, 41-61.

Gallup, G. G., \& Rager, D. R. (1996). Tonic immobility as a model of extreme states of behavioral inhibition. In P. R. Sanberg, K. P. Ossenkopp, \& M. Kavaliers (Eds.), Motor activity and movement disorders (pp. 57-80). Totowa, NJ: Human Press.

Gerard, C. M., Harris, K. A., \& Thach, B. T. (2002). Spontaneous arousals in supine infants while swaddled and unswaddled during rapid eye movement and quiet sleep. Pediatrics, 110(6), e70.

Giannico, A. T., Lima, L., Lange, R. R., Froes, T. R., \& MontianiFerreira, F. (2014). Proven cardiac changes during death-feigning (tonic immobility) in rabbits (Oryctolagus cuniculus). Journal of Comparative Physiology, 200(4), 305-310.

Gliga, T., \& Csibra, G. (2007). Seeing the face through the eyes: a developmental perspective on face expertice. Progress in Brain Research, 164, 323-339.

Gold, A. L., Morey, R. A., \& McCarthy, G. (2015). Amygdala-prefrontal cortex functional connectivity during threat-induced anxiety and goal distraction. Biological Psychiatry, 77(4), 394- 403.

Goddard, S. (2005). Reflexes, learning and behavior: a window into the childs Mind. Fern Ridge Press.

Gorzalka, B. B., \& Lester, G. L. L. (1987). Oxytocin-induced facilitation of lordosis behaviour is progesterone-dependent. Neuropeptides, $10(1), 55-65$.

Gould, S. J. (1980). The Panada's thumb. More reflections in natural history. New York: W. W. Norton \& Company.

Grant, E. C. (1963). An analysis of the social behaviour of the male laboratory rat. Behaviour, 21, 260-281.

Grant, E. C., \& Mackintosh, J. H. (1963). A comparison of the social postures of some laboratory rodents. Behaviour, 21, 246-259.

Gray, J. A. (1982). Précis of "The neuropsychology of anxiety: an enquiry into the functions of the septo-hippocampal system". The Behavioral and Brain Sciences, 5, 469-534.

Gray, J. A. (1994). Personality dimensions and emotion systems. In P. Ekman \& R. Davidson (Eds.), The nature of emotions: fundamental questions (pp. 329-331). Oxford, UK: Oxford University Press.

Gray, J. A., \& McNaughton, N. (1983). Comparison between the behavioral effects of septal and hippocampal lesions: a review. Neuroscience and Biobehavioral Reviews, 7(2), 119-188.

Gray, J. A., \& McNaughton, N. (2008). The neuropsychology of anxiety. an enquiry into the functions of the septo-hippocampal system (2nd ed.). Oxford, UK: Oxford University Press.

Green, L., Fein, D., Modahl, C., Feinstein, C., Waterhouse, L., \& Morris, M. (2001). Oxytocin and autistic disorder: alterations in peptide forms. Biological Psychiatry, 50(8), 609-613.

Green, J. J., \& Hollander, E. (2010). Autism and oxytocin: new developments in translational approaches to therapeutics. Neurotherapeutics, 7(3), 250-257.

Green, S. A., Hernandez, L., Tottenham, N., Krasileva, K., Bookheimer, S. Y., \& Dapretto, M. (2015). Neurobiology of sensory overresponsivity in youth with autism spectrum disorders. JAMA Psychiatry, 72(8), 778-786.

Grewen, K. M., \& Light, K. C. (2011). Plasma oxytocin is related to lower cardiovascular and sympathetic reactivity to stress. Biological Psychology, 87(3), 340-349.

Gruzeler, J. H. (1998). A working model of the neurophysiology of hypnosis: a review of evidence. Contemporary Hypnosis, 15(1), 3-21.

Guastella, A. J., Mitchell, P. B., \& Dadds, M. R. (2008). Oxytocin increases gaze to the eye region of human faces. Biological Psychiatry, 63(1), 3-5.

Gunnar, M., \& Quevedo, K. (2007). The neurobiology of stress and development. Annual Review of Psychology, 58, 145-173.

Hall, M. E., \& Dawson, P. (1998). The submission reflex. Huntington, NY: Kroshka Books.

Hahn-Holbrook, J., Holt-Lunstad, J., Holbrook, C., Coyne, S. M., \& Lawson, E. T. (2011). Maternal defense: breast feeding increases 
aggression by reducing stress. Psychological Science, 22(10), 12881295.

Hare, B. (2007). From nonhuman to human mind. What changed and why? Current Directions in Psychological Science, 16(2), 60-64.

Hare, B., \& Tomasello, M. (2005). Human-like social skills in dogs? Trends in Cognitive Sciences, 9(9), 439-444.

Hare, B., Wobber, V., \& Wrangham, R. (2012). The self-domestication hypothesis: evolution of bonobo psychology is due to selection against aggression. Animal Behaviour, 83(3), 573-585.

Harlow, H. F. (1963). The maternal affectional system. In B. M. Foss (Ed.), Determinants of infant behaviour (Vol. 2, pp. 3-33). London: Methuen and Co..

Hartmann, E. (1998). Dreams and nightmares: the origin and meaning of dreams. New York: Perseus Publishing.

Hasselmo, M. (2005). What is the function of hippocampal theta rhythm? Linking behavioral data to phasic properties of field potential and unit recording data. Hippocampus, 15(7), 936-949.

Hasselmo, M. (2006). The role of acetylcholine in learning and memory. Current Opinion in Neurobiology, 16(6), 710-715.

Hayne, H. (2004). Infant memory development: implications for childhood amnesia. Developmental Review, 24(1), 33-73.

Haxby, J. V., Hoffman, E. A., \& Gobbini, M. I. (2002). Human neural systems for face recognition and social communication. Biological Psychiatry, 51(1), 59-67.

Heidt, J. M., Marx, B. P., \& Forsyth, J. P. (2005). Tonic immobility and childhood sexual abuse: a preliminary report evaluating the sequela of rape-induced paralysis. Behaviour Research and Therapy, 43(9), 1157-1171.

Heinrichs, M., Meinlschmidt, G., Wippich, W., Ehlert, U., \& Hellhammer, D. H. (2004). Selective amnesic effects of oxytocin on human memory. Physiology and Behavior, 83(1), 31-38.

Heinzeller, T., Joshi, B. N., Nürnberger, F., \& Reiter, R. J. (1988). Effects of aggressive encounters on pineal melatonin formation in male gerbils (Meriones unguiculatus, Cricetidae). Journal of Comparative Physiology, 164(1), 91-94.

Hennig, C. W. (1977). Effects of simulated predation on tonic immobility in Anolis carolinensis: the role of eye contact. Bulletin of the Psychonomic Society, 9(4), 239-242.

Hennig, C. W. (1978). Tonic immobility in the squirrel monkey (Saimiri sciureus). Primates, 19(2), 333-342.

Hennig, C. W., Dunlap, W. P., \& Harston, C. T. (1979). Tonic immobility and skin color in anoles: effects of serotonin precursors and metabolites. Physiology and Behavior, 22(6), 1079-1088.

Hennig, C. W., Harston, C. T., \& Dunlap, W. P. (1980). Blockade of the melatonin potentiation of tonic immobility in chickens by methysergide and cyproheptadine. Behavioral and Neural Biology, 29(3), 372-377.

Herman, M. D., Denlinger, S. L., Patarca, R., Katz, L., \& Hobson, J. A. (1991). Developmental phases of sleep and motor behaviour in a cat mother-infant system: a time-lapse video approach. Canadian Journal of Psychology, 45(2), 101-114.

Hindmarsh, K. W., Sankaran, K., \& Watson, V. G. (1984). Plasma betaendorphin concentrations in neonates associated with acute stress. Developmental Pharmacology and Therapeutics, 7(3), 198-204.

Hobson, A. J. (1999). Dreaming as delirium: how the brain goes out of its mind. Cambridge, MA: MIT Press.

Hobson, A. J. (2009). REM sleep and dreaming: towards a theory of protoconsciousness. Nature Reviews, 10(11), 803-813.

Hofer, M. A. (1987). Early social relationships: a psychobiologists view. Child Development, 58(3), 633-647.

Hoffman, M. (2013). The human frontal lobes and frontal network systems: an evolutionary, clinical, and treatment perspective. ISRN Neurology, 2013, 892459

Hoffman, J. W., Benson, H., Arns, P. A., Stainbrook, G. L., Landsberg, G. L., Young, J. B., \& Gill, A. (1982). Reduced sympathetic nervous system responsivity associated with the relaxation response. Science, 215(4529), 190-192.

Hollocks, M. J., Howlin, P., Papadopoulos, A. S., Khondoker, M., \& Simonoff, E. (2014). Differences in HPA-axis and heart rate responsiveness to psychosocial stress in children with autism spectrum disorders with and without co-morbid anxiety. Psychoendocrinology, 46, 32-45.

Holloway, R. L. (1981). Culture, symbols, and human brain evolution: a synthesis. Dialectical Anthropology, 5(4), 287-303.

Holmes-McNarry, M. Q., Cheng, W. L., Mar, M. H., Fussell, S., \& Zeisel, S. H. (1996). Choline and choline esters in human and rat milk and in infant formulas. The American Journal of Clinical Nutrition, 64(4), 572-576.

Honda, K., Negoro, H., Fukuoka, T., Higuchi, T., \& Uchide, K. (1985). Effect of microelectrophoretically applied acetylcholine, noradrenaline, dopamine and serotonin on the discharge of paraventricular oxytocinergic neurones in the rat. Endocrinologia Japonica, 32 (1), 127-133.

Hong, C. C., Harris, J. C., Pearlson, G. D., Kim, J. S., Calhoun, V. D., Fallon, J. H., Golay, X., Gillen, J. S., Simmonds, D. J., van Zijl, P. C., Zee, D. S., \& Pekar, J. J. (2009). fMRI evidence for multisensory recruitment associated with rapid eye movements during sleep. Human Brain Mapping, 30(5), 1705-1722.

Hoskovec, J., \& Svorad, D. (1969). The relationship between human and animal hypnosis. American Journal of Clinical Hypnosis, 11(3), $180-182$.

Hrncic, D., Rasic-Markovic, A., Bjekic-Macut, J., Susic, V., Djuric, D., \& Stanojlovic, O. (2013). Paradoxical sleep deprivation potentiates epilepsy induced by homocysteine thiolactone in adult rats. Experimental Biology \& Medicine, 238(1), 77-83.

Hughes, C., \& Ensor, R. (2007). Executive function and theory of mind: predictive relations from ages 2 to 4. Developmental Psychology, 43(6), 1447-1459.

Hull, C. L. (1933). Hypnosis and suggestibility: an experimental approach. Carmarthen: Crown House Publishing.

Humphreys, K. L., Sauder, C. L., Martin, E. K., \& Marx, B. P. (2010). Tonic immobility in childhood sexual abuse survivors and its relationship to posttraumatic stress symptomatology. Journal of Interpersonal Violence, 25(2), 358-373.

Ilcol, Y. O., Ozbek, R., Hamurtekin, E., \& Ulus, I. H. (2005). Choline status in newborns, infants, children, breast-feeding women, breastfed infants, and human breast milk. Journal of Nutritional Biochemsitry, 16(8), 489-499.

Jacobs, G. D. (2001). Clinical applications of the relaxation response and mind-body interventions. Journal of Alternative and Complementary Medicine, 7(suppl 1), S93-101.

Jensen, M. P., Adachi, T., \& Hakimian, S. (2015). Brain oscillations, hypnosis, and hypnotizability. American Journal of Clinical Hypnosis, 57(3), 230-253.

Jongen-Relo, A. L., \& Amaral, D. G. (1998). Evidence for a GABAergic projection from the central nucleus of the amygdala to the brainstem of the macaque monkey: a combined retrograde tracing and in situ hybridization study. European Journal of Neuroscience, 10, 2924 2933.

Jones, E. J., Venema, K., Lowy, R., Earl, R. K., \& Webb, S. J. (2015). Developmental changes in infant brain activity during naturalistic social experiences. Developmental Psychobiology, 57(7), 842-853.

Josselyn, S. A., \& Frankland, P. W. (2012). Infantile amnesia: a neurogenic hypothesis. Learning \& Memory, 19(9), 423-433.

Jhou, T. (2005). Neural mechanisms of freezing and passive aversive behaviors. The Journal of Comparative Neurology, 493(1), 111114.

Jouvet, M. (1973). Essai sur le reve. Archives of Italian Biology, 111, 564 576 article in French.

Jouvet, M. (1999). The paradox of sleep: the story of dreaming. Cambridge, MA: MIT Press. 
Juszczak, M. (1998). Melatonin affects the oxytocin and prolactin responses to stress in male rats. Journal of Physiology and Pharmacology, 49, 151-163.

Kahn, D., \& Hobson, A. J. (2005). Theory of mind in dreaming: awareness of feelings and thoughts of others in dreams. Dreaming, 15(1), $48-57$.

Kalin, N. H., Shelton, S. E., \& Lynn, D. E. (1995). Opiate systems in mother and infant primates coordinate intimate contact during reunion. Psychoneuroendocrinology, 20(7), 735-742.

Kallio, S., Hyönä, J., Revonsuo, A., Sikka, P., \& Nummenmaa, L. (2011). The existence of a hypnotic state revealed by eye movements. PloS One, 6(10), e26374.

Kanner, L. (1943). Autistic disturbances of affective contact. Nervous Child, 2, 217-250.

Karvat, G., \& Kimchi, T. (2014). Acetylcholine elevation relieves cognitive rigidity and social deficiency in a mouse model of autism. Neuropsychopharmacology, 39(4), 831-840.

Kagan, J. (1982). Psychological research on the human infant: an evaluative summary. New York: W. T. Grant Foundation.

Karmiloff-Smith, A. (1994). Précis of beyond modularity: a developmental perspective on cognitive science. Behavioral and Brain Sciences, 17(4), 693-745.

Kendon, A. (1967). Some functions of gaze-direction in social interaction. Acta Psychologica, 26(1), 1-47.

Kenkel, W. M., Paredes, J., Lewis, G. F., Yee, J. R., Pournajafi-Nazarloo, H., Grippo, A. J., Porges, S. W., \& Carter, C. S. (2013). Autonomic substrates of the response to pups in male praire voles. PloS One, 8(8), e69965.

Kirsch, P., Esslinger, C., Chen, Q., Mier, D., Lis, S., Siddhanti, S., Gruppe, H., Mattay, V. S., Gallhofer, B., \& Mayer-Lindenberg, A. (2005). Oxytocin modulates neural circuitry for social cognition and fear in humans. The Journal of Neuroscience, 25(49), 11489-11493.

Klemm, W. R. (2001). Behavioral arrest: In search of the neural control system. Progress in Neurobiology, 65(5), 453-471.

Klemm, W. R. (2011). Why does REM sleep occur? A wake-up hypothesis. Frontiers in Systems Neuroscience, 5, 73.

Kohen, D. P., \& Olness, K. (2012). Hypnosis and hypnotherapy with children (4th ed.). London: Routledge.

Koenigs, M., Young,L., Adolphs,R., Tranel, D., Cushman, F., Hauser, M., \& Damasio, M. (2007). Damage to the prefrontal cortex increases utilitarian moral judgements. Nature, 446 (7138): 908-911.

Koenings, M. (2012). The role of prefrontal cortex in psychopathy. Reviews in the Neurosciences, 23(3), 253-262.

Kosfeld, M., Heinrichs, M., Zak, P. J., Fischbacher, U., \& Fehr, E. (2005). Oxytocin increases trust in humans. Nature, 435(7042), 673-676.

Kovács, G. L., \& Telegdy, G. (1982). Role of oxytocin in memory and amnesia. Pharmacology and Therapeutics, 18(3), 375-395.

Kozlowska, K., Walker, P., \& Carrive, P. (2015). Fear and the defense cascade: clinical implications and management. Harvard Review of Psychiatry, 23(4), 263-287.

Kramis, R., Vanderwolf, C. H., \& Bland, B. H. (1975). Two types of hippocampal rhythmical slow activity in both the rabbit and the rat: relations to behavior and effects of atropine, diethyl ether, urethane, and pentobarbital. Experimental Neurology, 49(1 Pt 1), 5885.

Krojanker, R. (1969). Human hypnosis, animal hypnotic states, and the induction of sleep in infants. American Journal of Clinical Hypnosis, 11(3), 178-179.

Künzl, C., \& Sachser, N. (1999). The behavioral endocrinology of domestication: a comparison between the domestic guinea pig (Cavia aperea f. porcellous) and its wild ancestor, the cavy (Cavia aperea). Hormones and Behavior, 35(1), 28-37.

Kuo, M. F., Grosch, J., Fregni, F., Paulus, W., \& Nitsche, M. A. (2007). Focusing effect of acetylcholine on neuroplasticity in the human motor cortex. The Journal of Neuroscience, 27(52), 14442-14447.
Kushki, A., Drumm, E., Pla Mobarak, M., Tanel, N., Dupuis, A., Chau, T., \& Anagnostou, E. (2013). Investigating the autonomic nervous system response to anxiety in children with autism spectrum disorders. PloS One, 8(4), e59730.

Kustov, A., \& Robinson, D. (1996). Shared neural control of attentional shifts and eye movements. Nature, 384(6604), 74-77.

Lai, Y. Y., \& Siegel, J. M. (1990). Muscle tone suppression and stepping produced by stimulation of midbrain and rostral pontine reticular formation. The Journal of Neuroscience, 10(8), 2727-2734

Lancel, M., Krömer, S., \& Neumann, I. D. (2003). Intracerebral oxytocin modulates sleep-wake behaviour in male rats. Regulatory Peptides, 114(2-3), 145-152.

Langley, E. A., Krykbaeva, M., Blusztajn, J. K., \& Mellot, T. J. (2015). High maternal choline consumption during pregnancy and nursing alleviates deficits in social interaction and improves anxiety-like behaviors in the BTBR T+ltpr3tf/J mouse model of autism. Behavioral \& Brain Research, 278, 210-220.

Lauder, J., \& Schambra, U. (1999). Morphogenetic roles of acetylcholine. Environmental Health Perspectives, 107, 65-69.

Lee, M., Martin-Ruiz, C., Graham, A., \& Perry, E. (2002). Nicotinic receptor abnormalities in the cerebellar cortex in autism. Brain, 125(Pt 7), 1483-1495.

Lee, S. Y., Lee, A. R., Hwangbo, R., Han, J., Hong, M., \& Bahn, G. H. (2015). Is oxytocin application for autism spectrum disorder evidence-based? Experimental Neurobiology, 24(4), 312-324.

Leclair-Visonneau, L., Oudiette, D., Gaymard, B., Leu-Semenescu, S., \& Arnulf, I. (2010). Do the eyes scan dream images during rapid eye movement sleep? Evidence from the rapid eye movement sleep behaviour disorder model. Brain, 133(6), 1737-1746.

LeDoux, J. E. (1996). The emotional brain. New York: Simon \& Schuster.

Leifer, G. (2012). Maternity nursing: an introductory text. St. Louis: Elsevier.

Leigh, R. J., \& Zee, D. S. (1999). The neurology of eye movements (3rd ed.). Oxford: Oxford University Press.

Leite-Panissi, C. R., Coimbra, N. C., \& Menescal-de-Oliveira, L. (2003). The cholinergic stimulation of the central amygdala modifying the tonic immobility response and antinociception in guinea pigs depends on the ventrolateral periaqueductal gray. Brain Research Bulletin, 60(1-2), 167-178.

Leslie, A. M. (1987). Pretense and representation: the origins of "theory of mind". Psychological Review, 94(4), 412-426.

Leuschen, M. P., Willett, L. D., Bolam, D. L., \& Nelson Jr., R. M. (1991). Plasma beta-endorphin in neonates: effect of prematurity, gender, and respiratory status. Journal of Clinical Endocrinology and Metabolism, 73(5), 1062-1066.

Levine, P. A. (2010). In an unspoken voice: how the body releases trauma and restores goodness. Berkeley, CA: North Atlantic Books.

Liang, C. L., \& Marks, G. A. (2014). GABAA receptors are located in cholinergic terminals in the nucleus pontis oralis of the rat: implications for REM sleep control. Brain Research, 1543, 58-64.

Lieberman, M. D. (2013). Social: why our brains are wired to connect. New York: Broadway Books.

Lipton, E. L., Steinschneider, A., \& Richmond, J. B. (1965). Swaddling, a child care practice: historical, cultural, and experimental observation. Pediatrics, 35, 521-567.

Lohaus, A., Keller, H., \& Voelker, S. (2001). Relationship between eye contact, maternal sensitivity, and infant crying. International Journal of Behavioral Development, 25(6), 542-548.

Lunenburger, L., Kleiser, R., Stuphorn, V., Miller, L. E., \& Hoffmann, K. P. (2001). A possible role of the superior colliculus in eye-hand coordination. Progress in Brain Research, 134, 109-125.

Lynch, H. J., \& Deng, M. H. (1986). Pineal responses to stress. Journal of Neural Transmission, 21, 461-473. 
Löw, A., Weymar, M., \& Hamm, A. O. (2015). When threat is near, get out of here: dynamics of defensive behavior during freezing and active avoidance. Psychological Science, 26(11), 1706-1716.

MacAlister, A. R., \& Peterson, C. C. (2013). Siblings, theory of mind, and executive functioning in children aged 3-6 years: new longitudinal evidence. Child Development, 84(4), 1442-1458.

MacLean, P. D. (1990). The triune brain in evolution: role in paleocerebral functions. New York: Springer.

Maior, R. S., Hori, E., Uribe, C. E., Saletti, P. G., Ono, T., Nishijo, H., \& Tomaz, C. (2012). A role for the superior colliculus in the modulation of threat responsiveness in primates: toward the ontogenesis of the social brain. Reviews in the Neurosciences, 23(5-6), 697-706.

Mandler, J. M. (1998). Representation. In W. Damon, D. Kuhn, \& R. S. Siegler (Eds.), Handbook of child psychology. Volume 2: cognition, perception, and language (5th ed.). New York: John Wiley \& Sons, Inc..

Marshall-Pescini, S., Viranyi, Z., \& Range, F. (2015). The effect of domestication on inhibitory control: wolves and dogs compared. PloS One, 10(2), e0118469.

McCarthy, M. M., Chung, S. K., Ogawa, S., Kow, L. M., \& Pfaff, D. W. (1991). Behavioral effects of oxytocin: is there a unifying principle? In S. Jard \& R. Jamison (Eds.), Vasopressin (pp. 195-212). London: John Libbey.

McCleary, R. A. (1966). Response modulating function of the limbic system: initiation and suppression. In E. Stellar \& J. M. Sprague (Eds.), Progress in physiological psychology (Vol. 1, pp. 209271). San Diego, CA: Academic Press.

McCorry, L. K. (2007). Physiology of the autonomic nervous system. American Journal of Pharmaceutical Education, 71(4), 78.

McNamara, P., Andresen, J., Clark, J., Zborowski, M., \& Duffy, C. A. (2001). Impact of attachment styles on dream recall and dream content: a test of the attachment hypothesis of REM sleep. Journal of Sleep Research, 10(2), 117-127.

McNamara, P., McLaren, D., Kowalczyk, S., \& Pace-Schott, E. F. (2007). 'Theory of mind' in REM and non-REM dreams. In D. Barrett \& P. McNamara (Eds.), The new science of dreaming (pp. 201-221). Westport: Praeger Perspectives.

McNamara, P., Pace-Schott, E. F., Johnson, P., Harris, E., \& Auerbach, S. (2011). Sleep architecture and sleep-related mentation in securely and insecurely attached people. Attachment and Human Development, 13(2), 141-154.

Meltzoff, A. N., \& Brooks, R. (2007). Eyes wide shut: the importance of eyes in infant gaze following and understanding other minds. In R. Flom, K. Lee, \& D. Muir (Eds.), Gaze following: its development and significance (pp. 217-241). Mahwah, NJ: Erlbaum.

Meyer, M. E., Smith, R. L., \& van Hartesveldt, C. (1984). Haloperidol differentially potentiates tonic immobility, the dorsal immobility response, and catalepsy in the developing rat. Developmental Psychobiology, 17(4), 383-389.

Miaskowski, C., Ong, G. L., Lukic, D., \& Haldar, J. (1988). Immobilization stress affects oxytocin and vasopressin levels in hypothalamic and extrahypothalamic sites. Brain Research, 458(1), 137-141.

Michel, G. F., \& Goodwin, R. (1979). Intrauterine birth position predicts newborn supine head position preference. Infant Behavior and Development, 2(1), 29-38.

Miklosi, A., Polgardi, R., Topal, J., \& Csanyi, V. (1998). Use of experimenter-given cues in dogs. Animal Cognition, 1(2), 113-121.

Miles, W. (1929). Sleeping with the eyes open. Scientific American, 140(6), 489-492.

Miller, A. M., Obermyer, W. H., Behan, M., \& Benca, R. M. (1998). The superior colliculus-pretectum mediates the direct effects of light on sleep. Proceedings of the National Academy of Sciences of the U.S.A., 95(15), 8957-8962.
Miller, A. M., Miller, R. B., Obermyer, W. H., Behan, M., \& Benca, R. M. (1999). The pretectum mediates rapid eye movement sleep regulation by light. Behavioral Neuroscience, 113(4), 755-765.

Miller, R. (1991). Cortico-hippocampal interplay and representation of contexts in the brain. Berlin: Springer.

Mink, D., Henning, A., \& Aschersleben, G. (2014). Infant shy temperament predicts preschoolers theory of mind. Infant Behavior \& Development, 37(1), 66-75.

Modahl, C., Green, L., Fein, D., Morris, M., Waterhouse, L., Feinstein, C., \& Levin, H. (1998). Plasma oxytocin levels in autistic children. Biological Psychiatry, 43(4), 270-277.

Mongeau, R., Miller, G. A., Chiang, E., \& Anderson, D. J. (2003). Neural correlates of competing fear behaviors evoked by an innately aversive stimulus. The Journal of Neuroscience, 23(9), 3855-3868.

Montagu, A. (1986). Touching: the human significance of the skin (3rd ed.). New York: William Morrow.

Montagu, A. (1988). Growing young (2nd ed.). London: Praeger.

Morales, M., Mundy, P., Crowson, M. M., Neal, R. A., \& Delgado, C. E. F. (2005). Individual differences in infant attention skills, joint attention, and emotion regulation behaviour. International Journal of Behavioral Development, 29(3), 259-263.

Morita, H., Hass, C. J., Moro, E., Sudhyadhom, A., Kumar, R., \& Okun, M. S. (2014). Pedunculopontine nucleus stimulation: where are we now and what needs to be done to move the field forward? Frontiers in Neurology, 5, 243.

Morris, D. (1967). The naked ape: a zoologist's study of the human animal. New York, NY: Delta.

Moscardino, U., \& Axia, G. (2006). Infants' responses to arm restraint at 2 and 6 months: a longitudinal study. Infant Behavior \& Development, 29, 59-69.

Mukaetova-Ladinska, E. B., Westwood, J., \& Perry, E. K. (2010). Cholinergic component of autism spectrum disorder. In G. J. Blatt (Ed.), The neurochemical basis of autism. From molecules to minicolumns (pp. 129-161). Berlin: Springer.

Murchie, G. (1978). The seven mysteries of life. Boston: Houghton Mifflin.

Muroy, S. E., Long, K. L., Kaufer, D., \& Kirby, E. D. (2016). Moderate stress-induced social bonding and oxytocin signaling are disrupted by predator odor in male rats. Neuropsychopharmacology, 41(8), 2160-2170.

Nagasawa, M., Mitsui, S., En, S., Ohtani, N., Ohta, M., Sakuma, Y., Onaka, T., Mogi, K., \& Kikuisi, T. (2015). Social evolution. Oxytocin-gaze positive loop and the coevolution of human-dog bonds. Science, 348(6232), 333-336.

Naggar, A. N., \& Komisaruk, B. R. (1977). Facilitation of tonic immobility by stimulation of the vaginal cervix in the rat. Physiology and Behavior, 19(3), 441-444.

Nelson, E., \& Panksepp, J. (1998). Brain substrates of infant-mother attachment: contributions of opioids, oxytocin, and norepinephrine. Neuroscience \& Biobehavioral Reviews, 22(3), 437-452.

Nichols, K., \& Champness, B. (1971). Eye gaze and the GSR. Journal of Experimental Social Psychology, 7(6), 623-626.

Nykamp, K., Rosenthal, L., Folkerts, M., Roehrs, T., Guido, P., \& Roth, T. (1998). The effects of REM sleep deprivation on the level of sleepiness/alertness. Sleep, 21(6), 609-614.

Ondrejcakova, M., Bakos, J., Garafova, A., Kovacs, L., Kvetnansky, R., \& Jezova, D. (2010). Neuroendocrine and cardiovascular parameters during simulation of stress-induced rise in circulating oxytocin in the rat. The International Journal on the Biology of Stress, 13(4), 315-323.

Orekhova, E. V., Stroganova, T. A., Posikera, I. N., \& Elam, M. (2006). EEG theta rhythm in infants and preschool children. Clinical Neurophysiology, 117(5), 1047-1062.

Osadschuk, L. V. (1997). Effects of domestication on the adrenal cortisol production of silver foxes during embryonic development. In L. N. 
Trut \& L. V. Osadschuk (Eds.), Evolutionary-genetic and geneticphysiological aspects of fur animal domestication. Oslo: Scientifur.

Owen, M., \& Bliss, E. L. (1970). Sleep loss and cerebral excitability. American Journal of Physiology, 218(1), 171-173.

Pace-Schott, E. F. (2001). "Theory of mind", social cognition and dreaming. Sleep Research Society Bulletin, 7(2), 33-36.

Pace-Schott, E. F., \& Hobson, J. A. (2002). The neurobiology of sleep: genetics, cellular physiology and subcortical networks. Nature Reviews Neuroscience, 3, 591-605.

Panksepp, J. (1998). Affective neuroscience: the foundations of human and animal emotions. New York, NY: Oxford University Press.

Panksepp, J., \& Biven, L. (2012). The archaeology of mind: neuroevolutionary origins of human emotions. New York: W. W. Norton \& Company.

Park, E. G., Lee, J., Lee, B. L., Lee, M., \& Lee, J. (2015). Paroxysmal nonepileptic events in pediatric patients. Epilepsy \& Behavior, 48, 83-87.

Patterson, C. M., \& Newman, J. P. (1993). Reflectivity and learning from aversive events: Toward a psychological mechanism for the syndromes of disinhibition. Psychological Review, 100(4): 716-736.

Pease, A. S., Fleming, P. J., Hauck, F. R., Moon, R. Y., Horne, R. S. C., L'Hoir, M. P., Ponsonby, A. L., \& Blair, P. S. (2016). Swaddling and the risk of sudden infant death syndrome: a meta-analysis. Pediatrics, 137(6), e20153275.

Peiper, A. (1963). Cerebral function in infancy and childhood. New York: Consultants Bureau.

Perner, J., \& Lang, B. (1999). Development of theory of mind and executive control. Trends in Cognitive Sciences, 3(9), 337-344.

Perry, E. K., Lee, M. L. W., Ruiz, M., \& Wenk, G. L. (2001). Cholinergic activity in autism: abnormalities in the cerebral cortex and basal forebrain. American Journal of Psychiatry, 158(7), 1058-1066.

Pitcairn, T., \& Eibl-Eibesfeldt, I. (1976). Concerning the evolution of non-verbal communication in man. In M. Hahn \& E. Simmel (Eds.), Communicative behavior and evolution (pp. 81-114). New York: Academic Press.

Polgar, F. J. (1951). The story of a hypnotist (with Kurt Singer). New York: Hermitage House, Inc..

Porges, S. W. (1995). Orienting in a defensive world: mammalian modifications of our evolutionary heritage. A polyvagal theory. Psychophysiology, 32(4), 301-318.

Porges, S. W. (2003). Social engagement and attachment: a phylogenetic perspective. Annals of the New York Academy of Sciences, 1008, $31-47$.

Porges, S. W. (2011). The Polyvagal theory: neurophysiological foundations of emotions, attachment, communication, and self-regulation. New York: W. W. Norton \& Company.

Porro, C. A., \& Carli, G. (1988). Immobilization and restraint effects on pain reactions in animals. Pain, 32(3), 289-307.

Porter, F. L., Wolf, C. M., \& Miller, J. P. (1998). The effect of handling and immobilization on the response to acute pain in newborn infants. Pediatrics, 102(6), 1383-1389.

Power, A. E., \& McGaugh, J. L. (2002). Cholinergic activation of the basolateral amygdala regulates unlearned freezing behavior in rats. Behavioral Brain Research, 134(1-2), 307-315.

Premack, D., \& Woodruff, G. (1978). Does the chimpanzee have a theory of mind? The Behavioral and Brain Sciences, 1(4), 515-526.

Prestrude, A. M. (1977). Some phylogenetic comparisons of tonic immobility with special reference to habituation and fear. The Psychological Record, 27, 21-39.

Quingley, K. S., \& Stifter, C. A. (2006). A comparative validation of sympathetic reactivity in children and adults. Psychophysiology, 43(4), 357-365.

Rakshit, A., \& Klemm, W. R. (1980). Depth-duration profile of the immobility reflex: theoretical implications for its triggering, sustaining, and terminating mechanisms. Journal of Neuroscience Research, 5(3), 253-262.
Ratner, S. C. (1977). Immobility of invertebrates: what can we learn? The Psychological Record, 27, 1-13.

Raz, A. (2005). Attention and hypnosis: neural substrates and genetic associations of two converging processes. Journal of clinical and experimental hypnosis, 53(3), 237-258.

Revonsuo, A. (2000). The reinterpretation of dreams: an evolutionary hypothesis of the function of dreaming. Behavioral \& Brain Sciences, 23, 877-901.

Richardson, H. L., Walker, A. M., \& Horne, R. S. (2009). Minimizing the risks of sudden infant death syndrome: to swaddle or not to swaddle? Pediatrics, 155(4), 475-481.

Roffwarg, H. P., Muzio, J. N., \& Dement, W. C. (1966). Ontogenetic development of the human sleep-dream cycle. Science, 152(3722), 604-619.

Romero, T., Nagasawa, M., Mogi, K., Hasegawa, T., \& Kikusui, T. (2014). Oxytocin promotes social bonding in dogs. Proceedings of the National Academy of Sciences of the U.S.A., 111(25), 90859090 .

Rosenow, F., Wyllie, E., Kotagal, P., Mascha, E., Wolgamuth, B. R., \& Hamer, H. (1998). Staring spells in children: descriptive features distinguishing epileptic and nonepileptic events. The Journal of Pediatrics, 133(5), 660-663.

Rousseau, P. V., Francotte, J., Fabbricatore, M., Frischen, C., Duchateau, D., Perin, M., Gauthier, J. M., \& Lahaye, W. (2014). Immobility reaction at birth in newborn infant. Infant Behavior \& Development, 37(3), 380-386.

Rovee-Collier, C., Kupersmidt, J., O’Brien, L., Collier, G., \& Tepper, V. (1991). Behavioral thermoregulation and immobilization: conflicting demands for survival. Journal of Comparative Psychology, 105(3), 232-242.

Rubenstein, J. L. R., \& Merzenich, M. M. (2003). Model of autism: increased ratio of excitation/inhibition in key neural systems. Genes, Brain \& Behavior, 2(5), 255-267.

Sallinen, M., Härmä, M., Akila, R., Holm, A., Luukkonen, R., Mikola, H., Müller, K., \& Virkkala, J. (2004). The effects of sleep debt and monotonous work on sleepiness and performance during a 12-h dayshift. Journal of Sleep Research, 13(4), 285-294.

Sandoval-Herrera, V., Trujillo-Ferrara, J. G., Miranda-Páez, A., De La Cruz, F., \& Zamudio, S. R. (2011). Corticosterone microinjected into nucleus pontis oralis increases tonic immobility in rats. Hormones and Bahavior, 60(4), 448-456.

Sanford, L. D., Morrison, A. R., Ball, W. A., Ross, R. J., \& Mann, G. (1992). Varying expressions of alerting mechanisms in wakefulness and across sleep states. Electroencephalography and Clinical Neurophysiology, 82(6), 458-468.

Sainsbury, R. S., Heynen, A., \& Montoya, C. P. (1987). Behavioral correlates of hippocampal type 2 theta in the rat. Physiology and Behavior, 39(4), 513-519.

Schacter, D. L. (1977). EEG theta waves and psychological phenomena: a review and analysis. Biological Psychology, 5(1), 47-82.

Schenck, C. H. (2008). Sleep: a groundbreaking guide to the mysteries, the problems, and the solutions. New York, NY: Avery Books.

Schultz, J., Friston, K. J., O’Doherty, J., Wolpert, D. M., \& Frith, C. D. (2005). Activation in posterior superior temporal sulcus parallels parameter inducing the percept of animacy. Neuron, 45(4), 625-635.

Seeley, C. J., Smith, C. T., MacDonald, K.J., \& Beninger, R. J. (2016). Ventromedial prefrontal theta activity during rapid eye movement sleep is associated with improved decision-making on the Iowa Gambling Task. Behavioral Neuroscience, 130(3), 271-280.

Selye, H. (1936). A syndrome produced by diverse nocuous agents. Nature, 138, 32-32.

Selye, H. (1955). Stress and disease. Science, 122(3171), 625-631.

Senju, A., \& Johnson, M. H. (2009a). The eye contact effect: mechanisms and development. Trends in Cognitive Science, 13(3), 127-134. 
Senju, A., \& Johnson, M. H. (2009b). Atypical eye contact in autism: models, mechanisms and development. Neuroscience and Biobehavioral Reviews, 33(8), 1204-1214.

Shackman, A. J., McMenamin, B. W., Maxwell, J. S., Greischar, L. L., \& Davidson, R. J. (2009). Right dorsolateral prefrontal cortical activity and behavioral inhibition. Psychological Science, 20(12), 15001506.

Shapiro, F. (1989). Efficacy of the eye movement desensitization procedure in the treatment of traumatic memories. Journal of Traumatic Stress, 2(2), 199-223.

Shepherd, S. V. (2010). Following gaze: gaze-following behavior as a window into social cognition. Frontiers in Integrative Neuroscience, 4(5), 1-13.

Shimamura, A. P. (2000). The role of the prefrontal cortex in dynamic filtering. Psychobiology, 28(2), 207-218.

Sirota, A., Montgomery, S., Fujisawa, S., Isomura, Y., Zugaro, M., \& Buzsáki, G. (2008). Entrainment of neocortical neurons and gamma oscillations by the hippocampal theta rhythm. Neuron, 60(4), 683697.

Skinner, J. E., \& Yingling, C. D. (1977). Central gating mechanisms that regulate event-related potentials and behavior. In J. E. Desmedt (Ed.), Attention, voluntary contraction, and event-related cerebral potentials (progress in clinical neurophysiology, vol. 1) (pp. 30-69). Basel: Karger.

Slotkin, T. A., Kudlacz, E. M., Hou, Q. C., \& Seidler, F. J. (1990). Maturation of the sympathetic nervous system: role in neonatal physiological adaptations and in cellular development of peripheral tissues. In J. M. Cuezva, A. M. Pascual-Leone, \& M. S. Patel (Eds.), Endocrine and biochemical development of the fetus and neonate (pp. 67-75). London: Plenum Press.

Slotnick, B. M., \& Jarvik, M. E. (1966). Deficits in passive avoidance and fear conditioning in mice with septal lesions. Science, 154(3753), $1207-1208$

Smith, R. L., Webster, D. G., Van Hartesveldt, C., \& Meyer, M. E. (1985). Effects of estrus, estrogen-progesterone priming, and vaginal stimulation on tonic immobility, dorsal immobility, and lordosis in the female rat. Physiology and Behavior, 35(4), 577-581.

Smith, A. S., \& Wang, Z. (2014). Hypothalamic oxytocin mediates social buffering of the stress response. Biological Psychiatry, 76(4), 281288

Somel, M., Franz, H., Yan, Z., Lorenc, A., Guo, S., Giger, T., Kelso, J., Nickel, B., Dannemann, M., Bahn, S., Webster, M. J., Weickert, C. S., Lachmann, M., Pääbo, S., \& Khaitovich, P. (2009). Transcriptional neoteny in the human brain. Proceedings of the National Academy of Sciences of the U.S.A., 106(14), 5743-5748.

Spinner-Hansen, L., Gonzales, S. F., Toft, S., \& Bilde, T. (2008). Thanatosis as an adaptive male mating strategy in the nuptial giftgiving spider Pisaura mirabilis. Behavioral Ecology, 19(3), 546551.

Stoelb, B. L., Molton, I. R., Jensen, M. P., \& Patterson, D. R. (2009). The efficacy of hypnotic analgesia in adults: a review of the literature. Contemporary Hypnosis, 26(1), 24-39.

Suarez, S. D., \& Gallup, G. G. (1976). Tonic immobility as a response to rape in humans: a theoretical note. The Psychological Record, 29(3), 315-320.

Sugden, D., Davidson, K., Hough, K. A., \& Teh, M. T. (2004). Melatonin, melatonin receptors and melanophores: a moving story. Pigment Cell Research, 17(5), 454-460.

Sullivan, R. M., \& Gratton, A. (2002). Behavioral effects of excitotoxic lesions of ventral medial prefrontal cortex in the rat are hemispheredependent. Brain Research, 927(1), 69-79.

Svendsen, E. J., Moen, A., Pedersen, R., \& Björk, I. T. (2015). Resistive expressions in preschool children during peripheral vein cannulation in hospitals: a qualitative explorative observational study. $B M C$ Pediatrics, 15, 190.
Takakusaki, K., Habaguchi, T., Ohtinata-Sugimoto, J., Saitoh, K., \& Sakamoto, T. (2003). Basal ganglia efferents to the brainstem centers controlling postural muscle tone and locomotion: a new concept for understanding motor disorders in basal ganglia dysfunction. Neuroscience, 119(1), 293-308.

Takakusaki, K., Habaguchi, T., Saitoh, K., \& Kohyama, J. (2004). Changes in the excitability of hindlimb motorneurons during muscular atonia induced by stimulating the pedunculopontine tegmental nucleus in cats. Neuroscience, 124(2), 467-480.

Takeshita, H., Myowa-Yamakoshi, M., \& Hirata, S. (2009). The supine position of postnatal human infants. Implications for the development of cognitive intelligence. Interaction Studies, 10(2), 252-268.

Tebécis, A. K., \& Provins, K. A. (1975). Hypnosis and eye movements. Biological Psychology, 3(1), 31-47.

Teffer, K., \& Semendeferi, K. (2012). Human prefrontal cortex: evolution, development, and pathology. In M. A. Hofman \& D. Falk (Eds.), Evolution of the primate brain. From neuron to behavior (progress in brain research, vol. 195) (pp. 191-218). Amsterdam: Elsevier.

Teitelbaum, O., Benton, T., Shah, P. K., Prince, A., Kelly, J. L., \& Teitelbaum, P. (2004). Eshkol-Wachman movement notation in diagnosis: the early detection of Asperger's syndrome. Proceedings of the National Academy of Sciences of the U.S.A., 101(32), 11909 11914.

Teitelbaum, P., Teitelbaum, O., Nye, J., Fryman, J., \& Maurer, R. G. (1998). Movement analysis in infancy may be useful for early diagnosis of autism. Proceedings of the National Academy of Sciences of the U.S.A., 95(23), 13982-13987.

Teschke, E. J., Maser, J. D., \& Gallup, G. G. (1975). Cortical involvement in tonic immobility ("animal hypnosis"): effect of spreading cortical depression. Behavioral Biology, 13(1), 139-143.

Tessier, S., Lambert, A., Scherzer, P., Jemel, B., \& Godbout, R. (2015). REM sleep and emotional face memory in typically-developing children and children with autism. Biological Psychology, 110, 107-114.

Theodoridou, A., Rowe, A. C., Penton-Voak, I. S., \& Rogers, P. J. (2009). Oxytocin and social perception: oxytocin increases perceived facial trustworthiness and attractiveness. Hormones and Behavior, 56(1), $128-132$.

Thiffault, P., \& Bergeron, J. (2003). Monotony of road environment and driver fatigue: a simulator study. Accident Analysis and Prevention, 35(3), 381-391.

Thomas, A., \& Chess, S. (1977). Temperament and development. New York: Brunner-Routledge.

Thompson, R. W. (1977). A central cholinergic inhibition system as a basis for tonic immobility in chickens. The Psychological Record, $27,109-121$.

Thompson-Schill, S. L., Ramscar, M., \& Chrysikou, E. G. (2009). Cognition without control. When a little frontal lobe goes a long way. Current Directions in Psychological Science, 18(5), 259-263.

Trut, L. N., Plyusnina, I., \& Oskina, I. N. (2004). An experiment on fox domestication and debattable issues of evolution of the dog. Russian Journal of Genetics, 40(6), 644-655.

Trut, L. N., Oskina, I. N., \& Kharlamova, A. (2009). Animal evolution during domestication: the domesticated fox as model. BioEssays, 31(3), 349-360.

Tsoukalas, I. (2012). The origin of REM sleep: a hypothesis. Dreaming, 22(4), 253-283.

Uvnäs-Moberg, K. (1997). Oxytocin linked antistress effects - the relaxation and growth response. Acta Physiologica Scandinavica, 640(suppl), 38-42.

Uvnäs-Moberg, K. (1998). Antistress pattern induced by oxytocin. News in Physiological Sciences, 13, 22-25.

Uvnäs-Moberg, K., Handlin, L., \& Petersson, M. (2014). Self-soothing behaviors with particular reference to oxytocin release induced by non-noxious sensory stimulation. Frontiers in Psychology, 5, 1529. 
Yang, X. F., Xiao, Y., \& Xu, M. Y. (2008). Both endogenous and exogenous ACh plays antinociceptive role in the hippocampus CA1 of rats. Journal of Neural Transmission, 115(1), 1-6.

Yang, Y., Paspalas, C. D., Jin, L. E., Picciotto, M. R., Arnsten, A. F. T., \& Wang, M. (2013). Nicotinic a7 receptors enhance NMDA cognitive circuits in dorsolateral prefrontal cortex. Proceedings of the National Academy of Sciences of the U.S.A., 110(29), 12078-12083.

Yoshida, S., Esposito, G., Ohnishi, R., Tsuneoka, Y., Okabe, S., Kikusui, T., Kato, T., \& Kuroda, K. (2013). Transport response is a filialspecific behavioral response to maternal carrying in C57BL/6 mice. Frontiers in Zoology, 10(1), 50.

Young, A. W., Aggleton, J. P., Hellawell, D. J., Johnson, M., Broks, P., \& Hanley, J. R. (1995). Face processing impairments after amygdalectomy. Brain, 118, 15-24.

Valance, D., Després, G., Richard, S., Constantin, P., Mignon-Grasteau, S., Leman, S., Boissy, A., Faure, J. M., \& Leterrier, C. (2008). Changes in heart rate variability during a tonic immobility test in quail. Physiology and Behavior, 93(3), 512-520.

Valentino, R. J., \& van Bockstaele, E. (2015). Endogenous opioids: the downside of opposing stress. Neurobiology of Stress, 1, 23-32.

van der Helm, E., Yao, J., Dutt, S., Rao, V., Saletin, J. M., \& Walker, M. P. (2011). REM sleep de-potentiates amygdala activity to previous emotional experiences. Current Biology, 21(23), 2029-2032.

van der Kolk, B. A., McFarlane, A. C., \& Weisaeth, L. (2006). Traumatic stress: the effects of overwhelming experience on mind, body, and society. New York: Guilford Press.

Van Sleuwen, B. E., Engelberts, A. C., Boere-Boonekamp, M. M., Kuis, W., Schulpen, T. W., \& L'Hoir, M. P. (2007). Swaddling: a systematic review. Pediatrics, 120(4), 1097-1106.

Vernet, M., Quentin, R., Chanes, L., Mitsumasu, A., \& Valero-Cabré, A. (2014). Frontal eye field, where art thou? Anatomy, function, and non-invasive manipulation of frontal regions involved in eye movements and associated cognitive operations. Frontiers in Integrative Neuroscience, 8, 66.

Volchan, E., Souza, G., Franklin, C., Norte, C., Rocha-Rego, V., Oliveira, J., David, I., Mendlowicz, M., Coutinho, E., Fiszman, A., Berger, W., Marques-Portella, C., \& Figueira, I. (2011). Is there tonic immobility in humans? Biological evidence from victims of traumatic stress. Biological Psychology, 88(1), 13-19.

Volz, K. G., Schubotz, R. I., \& von Cramon, D. Y. (2005). Variants of uncertainty in decision-making and their neural correlates. Brain Research Bulletin, 67(5), 403-412.

Vrugt, D. T., \& Pederson, D. R. (1973). The effects of vertical rocking frequencies on the arousal level in two-month-old infants. Child Development, 44(1), 205-209.

Wada, J. A. (1961). Modification of cortically induced responses in brainstem of shift of attention in monkeys. Science, 133(3445), $40-42$.

Waldherr, M., \& Neumann, I. D. (2007). Centrally released oxytocin mediates mating-induced anxiolysis in male rats. Proceedings of the National Academy of Sciences of the U.S.A., 104(42), 1668116684.
Wallace, M. T., Meredith, M. A., \& Stein, B. E. (1998). Multisensory integration in the superior colliculus of the alert cat. The Journal of Neurophysiology, 80(2), 1006-1010.

Walker, M. P., \& van der Helm, E. (2009). Overnight therapy? The role of sleep in emotional brain processing. Psychological Bulletin, 135(5), 731-748.

Webster, D. G., Lanthorn, T. H., Dewsbury, D. A., \& Meyer, M. E. (1981). Tonic immobility and the dorsal immobility response in twelve species of muroid rodents. Behavioral and Neural Biology, 31(1), 32-41.

Wegner, D. M. (1997). Why the mind wanders. In J. D. Cohen \& J. W. Schooler (Eds.), Scientific approaches to consciousness (pp. 295315). Jersey City: Lawrence Erlbaum.

Weller, A., \& Feldman, R. (2003). Emotion regulation and touch in infants: the role of cholecystokinin and opioids. Peptides, 24(5), 779 788.

Wellman, H. M., Lane, J. D., LaBounty, J., \& Olson, S. L. (2011). Observant, nonaggressive temperament predicts theory of mind development. Developmental Science, 14(2), 319-326.

Whishaw, I. Q., Schallert, T., \& Kolb, B. (1979). The thermal control of immobility in developing infant rats: is the neocortex involved? Physiology \& Behavior, 23(4), 757-762.

Wilkins, A. S., Wrangham, R. W., \& Fitch, W. T. (2014). The "domestication syndrome" in mammals: a unified explanation based on neural crest cell behavior and genetics. Genetics, 197(3), 795-808.

Williams, G. W. (1963). Highway hypnosis: a hypothesis. International Journal of Clinical and Experimental Hypnosis, 11(3), 143-151.

Wilson, D., Silver, S. M., Covi, W., \& Foster, S. (1996). Eye movement desensitization and reprocessing: effectiveness and autonomic correlates. Journal of Behaviour Therapy and Experimental Psychiatry, 27(3), 219-229.

Winson, J. (1972). Interspecies differences in the occurrence of theta. Behavioral Biology, 7(4), 479-487.

Woodruff, M. L. (1977). Limbic modulation of contact defensive immobility ("animal hypnosis"). The Psychological Record, 27, 161-175.

Wu, M. F., \& Siegel, J. M. (1990). Facilitation of the acoustic startle reflex by ponto-geniculo-occipital waves: effects of PCPA. Brain Research, 532(1-2), 237-241.

Zafeiriou, D. I. (2004). Primitive reflexes and postural reactions in the neurodevelopmental examination. Pediatric Neurology, 31(1), 1-8.

Zak, P. J., Stanton, A. A., \& Ahmadi, S. (2007). Oxytocin increases generosity in humans. PloS One, 2(11), e1128.

Zanardo, V., Nicolussi, S., Carlo, G., Marzari, F., Faggian, D., Favaro, F., \& Plebani, M. (2001). Beta endorphin concentrations in human milk. Journal of Pediatric Gastroenterology and Nutrition, 33(2), 160-164.

Zborowski, M. J., \& McNamara, P. (1998). Attachment hypothesis of REM sleep: toward an integration of psychoanalysis, neuroscience, and evolutionary psychology and the implications for psychopathology research. Psychoanalytic Psychology, 15(1), 115-140.

Zeisel, S. H. (2006). Choline: critical role during fetal development and dietary requirements in adults. Annual Review of Nutrition, 26, 229-250.

Zhdanova, I. V., Lynch, H. J., \& Wurtman, R. J. (1997). Melatonin: a sleep-promoting hormone. Sleep, 20(10), 899-907. 